Supporting information for

\title{
Mitochondria-Targeted BODIPY Nanoparticles for Enhanced Photothermal and Photoacoustic Imaging in Vivo
}

Jiang-Lin Wang a, Lu Zhang a, Mei-Jiao Zhao ${ }^{\mathrm{b}}$, Tao Zhang *,b, Yi Liu ${ }^{\mathrm{a}, \mathrm{c}}$ and Feng-Lei Jiang *,a

a Sauvage Center for Molecular Sciences, College of Chemistry and Molecular Sciences, Wuhan University, Wuhan 430072, P. R. China

b MOE Key Laboratory of Laser Life Science \& Institute of Laser Life Science, Guangdong Provincial Key Laboratory of Laser Life Science, and College of Biophotonics, South China Normal University, Guangzhou 510631, P. R. China

c College of Chemistry and Chemical Engineering, Tiangong University, Tianjin 300387, P. R. China

*Corresponding Author. E-mail: fljiang@whu.edu.cn (F.-L. J.). Tel: +86-27-68756667.zt@scnu.edu.cn (T. Z.). 
Table S1. BODIPY-based photothermal agents and their photothermal conversion efficiencies (PCE).

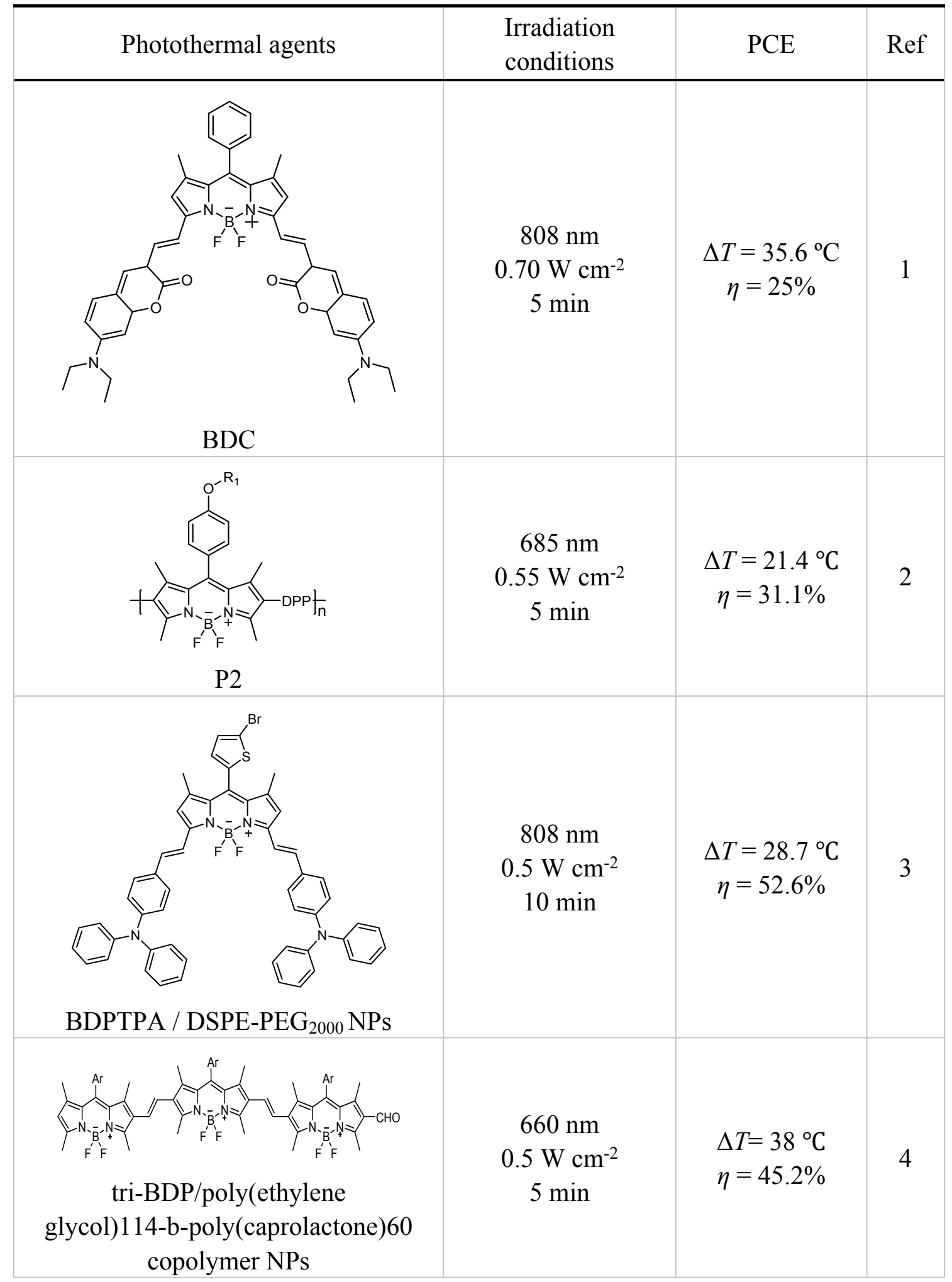




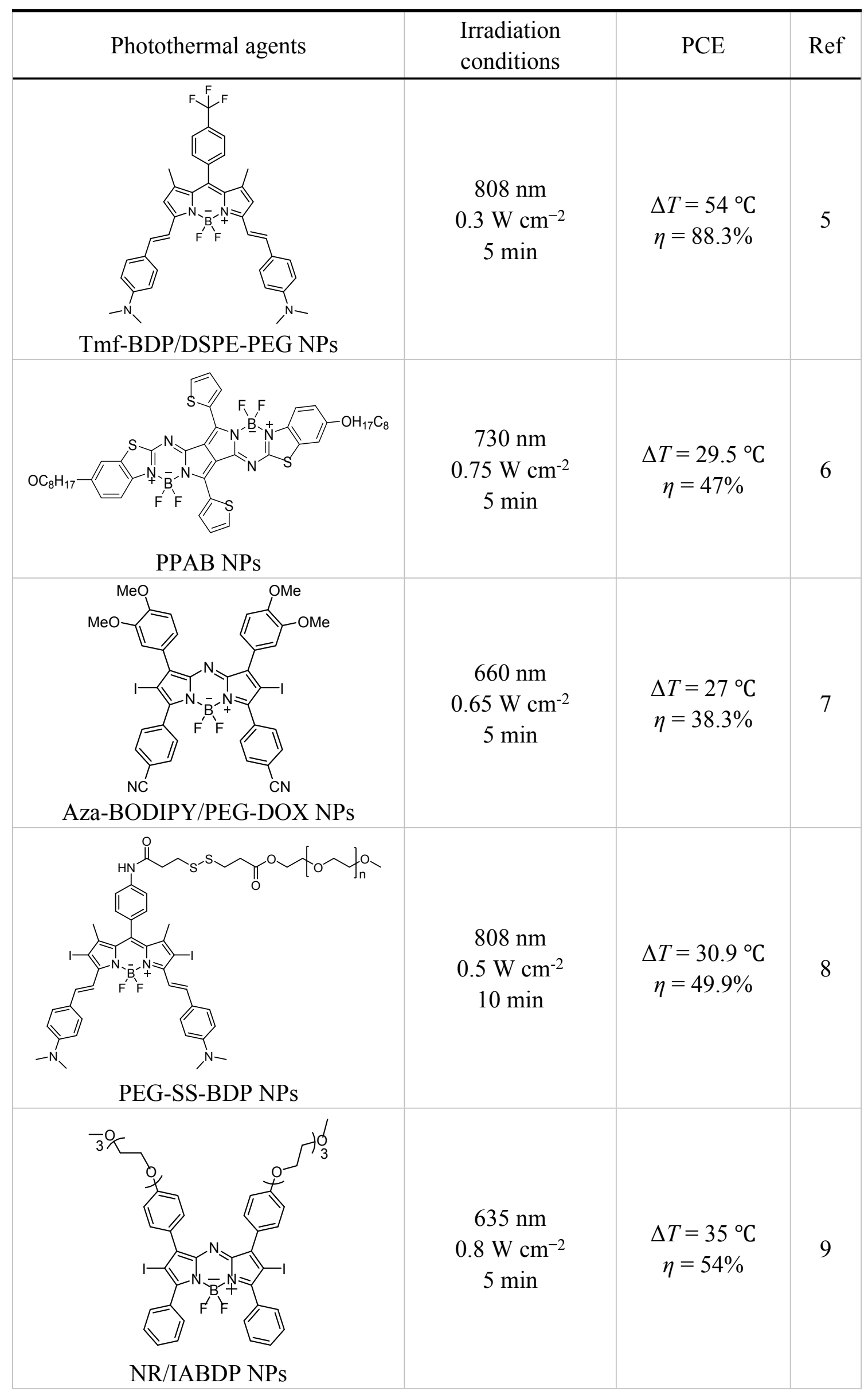




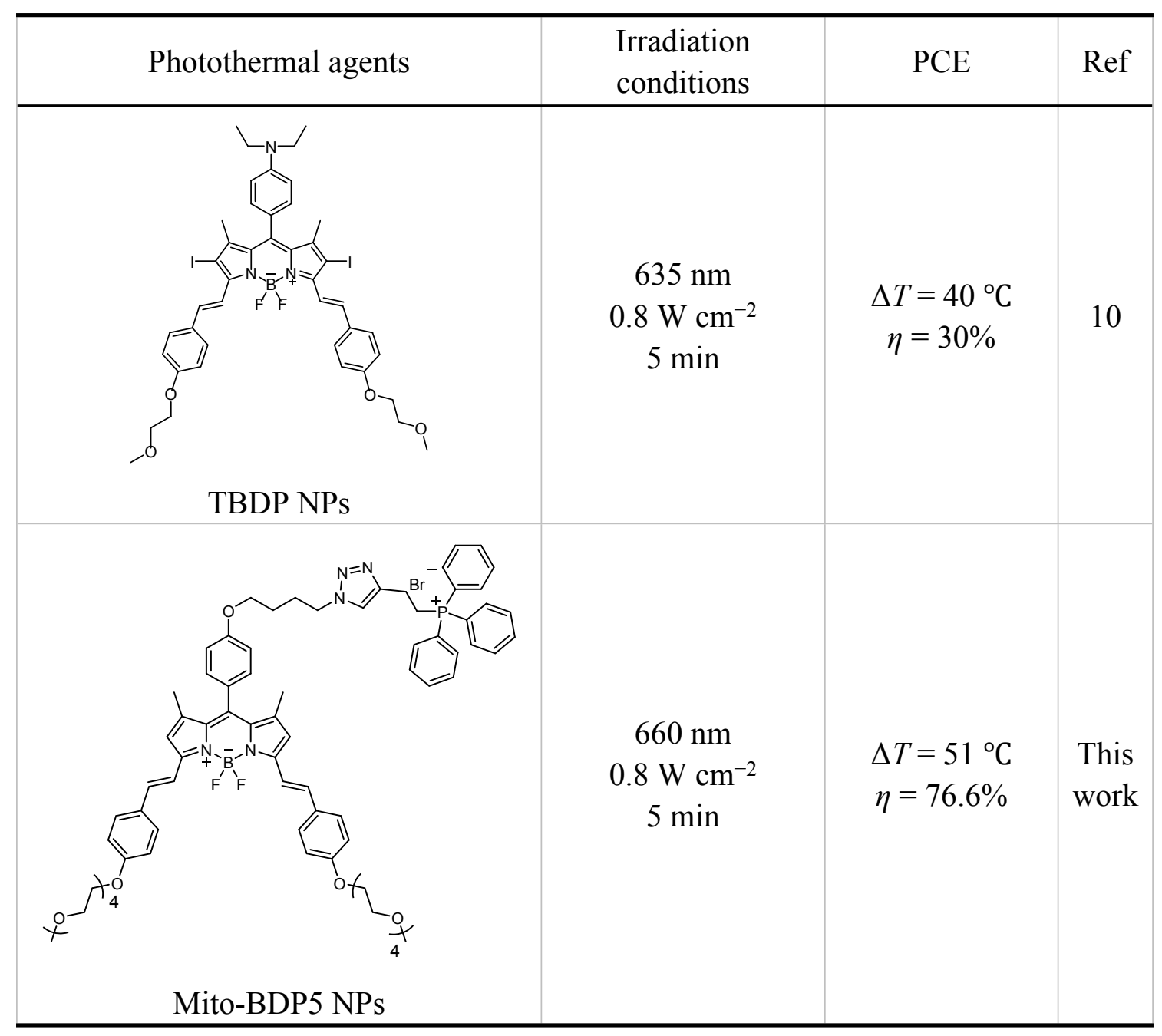




\section{Synthetic procedures}

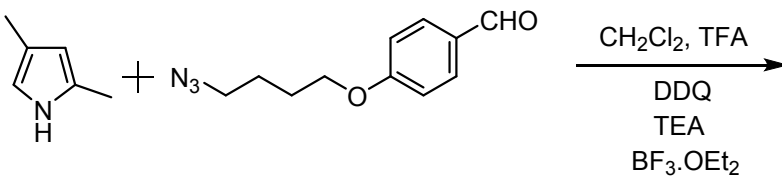

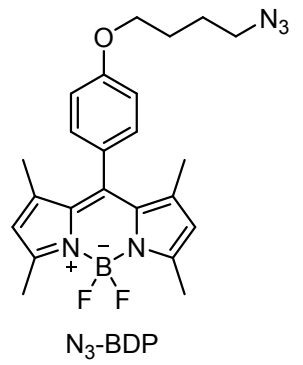

Scheme S1. Synthetic route for $\mathbf{N}_{3}-\mathbf{B D P}$.

N3-BDP: A drop of trifluoroacetic acid (TFA) was added to the mixture of 2,4-dimethylpyrrole (0.46 g, $4.8 \mathrm{mmol}, 2.0 \mathrm{eq})$ and compound 1 (0.48 g, $2.2 \mathrm{mmol}$, $1.0 \mathrm{eq}$ ) in $300 \mathrm{~mL}$ anhydrous $\mathrm{CH}_{2} \mathrm{Cl}_{2}$. The solution was stirred at room temperature for $12 \mathrm{~h}$ under argon atmosphere. Then, 2,3-Dichloro-5,6-dicyano-1,4-benzoquinone (DDQ, $0.54 \mathrm{~g}, 2.2 \mathrm{mmol}, 1.0 \mathrm{eq}$ ) was added to the reaction mixture and stirring was continued for about $30 \mathrm{~min}$. Triethylamine (TEA, $5 \mathrm{~mL})$ and $\mathrm{BF}_{3} \cdot \mathrm{OEt}_{2}(5 \mathrm{~mL})$ were dropwise added to the reaction solution. After $30 \mathrm{~min}$, water was added to quench the reaction. Then, the mixture solution was extracted with $\mathrm{CH}_{2} \mathrm{Cl}_{2}$ for three times, washed with saturated brine for three times, and dried with anhydrous sodium sulfate. The $\mathrm{CH}_{2} \mathrm{Cl}_{2}$ was evaporated under reduced pressure and the residual sticky solid was purified by column chromatography on silica gel using $\mathrm{CH}_{2} \mathrm{Cl}_{2} /$ petroleum ether $(v / v=$ $1: 2)$ as eluent to afford an orange-red solid product $(0.71 \mathrm{mmol}, 310 \mathrm{mg}, 33 \%) .{ }^{1} \mathrm{H}$ NMR (400 MHz, $\left.\mathrm{CDCl}_{3}\right) \delta=7.16(\mathrm{~d}, J=8.6 \mathrm{~Hz}, 2 \mathrm{H}), 6.99(\mathrm{~d}, J=8.6 \mathrm{~Hz}, 2 \mathrm{H}), 5.98$ $(\mathrm{s}, 2 \mathrm{H}), 4.05(\mathrm{t}, J=6.0 \mathrm{~Hz}, 2 \mathrm{H}), 3.40(\mathrm{t}, J=6.6 \mathrm{~Hz}, 2 \mathrm{H}), 1.99-1.78(\mathrm{~m}, 4 \mathrm{H}), 1.43(\mathrm{~s}$, $6 \mathrm{H}) \mathrm{ppm} .{ }^{13} \mathrm{C} \mathrm{NMR}\left(100 \mathrm{MHz}, \mathrm{CDCl}_{3}\right) \delta=159.41,155.28,143.18,141.83,131.85$, $129.23,127.12,121.13,115.01,67.27,51.21,26.52,25.78,14.63 \mathrm{ppm}$.

General Procedure for $\mathbf{N}_{\mathbf{3}}$-BDP1-5. Under argon atmosphere, $\mathbf{N}_{\mathbf{3}}$-BDP was dissolved in respective benzaldehyde (compound $2, \mathrm{n}=0,1,2,3,4)$. Then, several drops of piperidine were added to the reaction solution, followed by continuous stirring at the temperature listed below until the color of the solution changed from red to dark blue. The reaction was monitored by TLC, and upon completion the residue was purified by silica gel flash chromatography with the solvents listed below. 


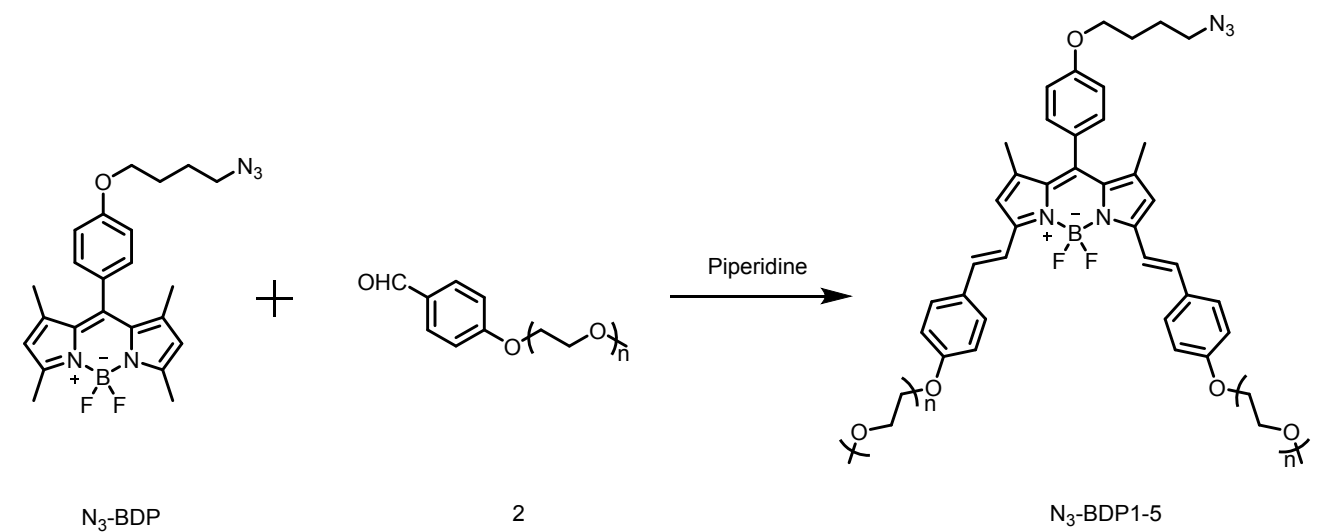

Scheme S2. Synthetic route for $\mathbf{N}_{3}-\mathbf{B D P 1 - 5}$.

N3-BDP1: N3-BDP (43.70 $\mathrm{mg}, \quad 0.01 \mathrm{mmol}, 1.0 \mathrm{eq})$ was reacted with 4-methoxybenzaldehyde (136.2 $\mathrm{mg}, 0.10 \mathrm{mmol}, 10 \mathrm{eq})$ at $60{ }^{\circ} \mathrm{C}$ for $6 \mathrm{~h}$. The obtained residual oil was purified by silica gel column chromatography and eluted with $\mathrm{CH}_{2} \mathrm{Cl}_{2}$ and petroleum ether $(v / v=1: 1)$ to produce dark blue powder $(34.1 \mathrm{mg}, 60 \%) .{ }^{1} \mathrm{H}$ NMR (400 MHz, $\left.\mathrm{CDCl}_{3}\right) \delta=7.69-7.47(\mathrm{~m}, 6 \mathrm{H}), 7.25-7.12(\mathrm{~m}, 4 \mathrm{H}), 7.03-6.85(\mathrm{~m}$, $6 \mathrm{H}), 6.61(\mathrm{~d}, J=5.1 \mathrm{~Hz}, 2 \mathrm{H}), 4.04(\mathrm{t}, J=5.7 \mathrm{~Hz}, 2 \mathrm{H}), 3.89-3.79(\mathrm{~m}, 6 \mathrm{H}), 3.39(\mathrm{t}, J=$ $6.5 \mathrm{~Hz}, 2 \mathrm{H}), 1.88$ (ddt, $J=33.0,14.1,6.6 \mathrm{~Hz}, 4 \mathrm{H}), 1.49$ (d, $J=4.8 \mathrm{~Hz}, 6 \mathrm{H}) \mathrm{ppm}$. ${ }^{13} \mathrm{C}-\mathrm{NMR}\left(100 \mathrm{MHz}, \mathrm{CDCl}_{3}\right) \delta=160.36,159.37,152.55,141.86,138.22,135.65$, $133.57,129.75,129.57,129.04,127.36,117.42,117.25,114.90,114.27,67.28,55.41$, $51.23,31.65,29.66,26.53,25.79,14.89 \mathrm{ppm}$.

N3-BDP2: N3-BDP (43.70 $\mathrm{mg}, 0.01 \mathrm{mmol}, 1.0 \mathrm{eq})$ was reacted with 4-(2-propoxyethoxy)benzaldehyde $(360.4 \mathrm{mg}, 0.20 \mathrm{mmol}, 20 \mathrm{eq})$ at $65{ }^{\circ} \mathrm{C}$ for $6.5 \mathrm{~h}$. The obtained residual oil was purified by silica gel column chromatography and eluted with $\mathrm{CH}_{2} \mathrm{Cl}_{2}$ and petroleum ether $(v / v=2: 1)$ to produce dark blue powder (47.2 mg, 77 \%). ${ }^{1} \mathrm{H}$ NMR (400 MHz, $\left.\mathrm{CDCl}_{3}\right) \delta=7.67-7.52(\mathrm{~m}, 6 \mathrm{H}), 7.20$ (dd, $J=12.4$, $3.7 \mathrm{~Hz}, 4 \mathrm{H}), 6.98(\mathrm{dd}, J=15.0,8.7 \mathrm{~Hz}, 6 \mathrm{H}), 6.61(\mathrm{~s}, 2 \mathrm{H}), 4.20-4.14(\mathrm{~m}, 4 \mathrm{H}), 4.05$ (t, $J=5.9 \mathrm{~Hz}, 2 \mathrm{H}), 3.78(\mathrm{dd}, J=5.3,3.9 \mathrm{~Hz}, 4 \mathrm{H}), 3.48(\mathrm{~s}, 6 \mathrm{H}), 2.01-1.79$ (m, 4H), 1.49 (s, 6H) ppm. ${ }^{13} \mathrm{C}$ NMR (100 MHz, $\left.\mathrm{CDCl}_{3}\right) \delta=159.54,159.37,152.56,141.84,138.22$, $135.62,133.58,129.76,129.02,127.40,122.34,117.42,117.34,114.90,70.97,67.33$, $67.28,59.31,51.22,26.53,25.79,14.90 \mathrm{ppm}$.

N3-BDP3: N3-BDP (43.70 $\mathrm{mg}, 0.01 \mathrm{mmol}, 1.0 \mathrm{eq})$ was reacted with 4-(2-(2-ethoxyethoxy)ethoxy)benzaldehyde $(672.9 \mathrm{mg}, 0.30 \mathrm{mmol}, 30 \mathrm{eq})$ at $70{ }^{\circ} \mathrm{C}$ for 
$5 \mathrm{~h}$. The obtained residual oil was purified by silica gel column chromatography and eluted with $\mathrm{CH}_{2} \mathrm{Cl}_{2}$ and $\mathrm{MeOH}(v / v=100: 1)$ to produce dark blue powder (51.7 $\mathrm{mg}$, 76 \%). ${ }^{1} \mathrm{H}$ NMR (400 MHz, $\left.\mathrm{CDCl}_{3}\right) \delta=7.71-7.48$ (m, 4H), $7.24-7.14(\mathrm{~m}, 4 \mathrm{H}), 6.97$ $(\mathrm{dd}, J=21.2,8.7 \mathrm{~Hz}, 6 \mathrm{H}), 6.61(\mathrm{~s}, 2 \mathrm{H}), 4.20(\mathrm{t}, J=4.9 \mathrm{~Hz}, 4 \mathrm{H}), 4.05$ (t, $J=5.9 \mathrm{~Hz}$, 2H), $3.89(\mathrm{t}, J=4.8 \mathrm{~Hz}, 4 \mathrm{H}), 3.74(\mathrm{dd}, J=5.6,3.6 \mathrm{~Hz}, 4 \mathrm{H}), 3.64-3.57$ (m, 4H), 3.41 (s, 6H), $2.00-1.78(\mathrm{~m}, 4 \mathrm{H}), 1.49(\mathrm{~s}, 6 \mathrm{H}) \mathrm{ppm} .{ }^{13} \mathrm{C} \mathrm{NMR}\left(100 \mathrm{MHz}, \mathrm{CDCl}_{3}\right) \delta=$ $159.56,159.37,152.57,141.83,138.20,135.63,133.58,129.76,129.71,129.01$, $127.41,117.41,114.91,71.97,70.82,69.73,67.48,67.28,59.16,51.23,26.54,25.79$, $14.90 \mathrm{ppm}$.

N3-BDP4: N3-BDP (43.70 $\mathrm{mg}, \quad 0.01 \mathrm{mmol}, 1.0 \mathrm{eq})$ was reacted with 4-(2-(2-(2-ethoxyethoxy)ethoxy)ethoxy)benzaldehyde (1.073 g, $0.40 \mathrm{mmol}, 40 \mathrm{eq})$ at $70{ }^{\circ} \mathrm{C}$ for $6 \mathrm{~h}$. The obtained residual oil was purified by silica gel column chromatography and eluted with $\mathrm{CH}_{2} \mathrm{Cl}_{2}$ and $\mathrm{MeOH}(v / v=100: 1)$ to give dark blue waxy solid (55.5 mg, $78 \%$ \%). ${ }^{1} \mathrm{H}$ NMR (400 MHz, $\left.\mathrm{CDCl}_{3}\right) \delta=7.67-7.48(\mathrm{~m}, 6 \mathrm{H})$, $7.24-7.16(\mathrm{~m}, 4 \mathrm{H}), 6.97(\mathrm{dd}, J=22.2,8.6 \mathrm{~Hz}, 6 \mathrm{H}), 6.61(\mathrm{~s}, 2 \mathrm{H}), 4.18(\mathrm{t}, J=4.8 \mathrm{~Hz}$, 4H), $4.06(\mathrm{t}, J=5.9 \mathrm{~Hz}, 2 \mathrm{H}), 3.93-3.85(\mathrm{~m}, 4 \mathrm{H}), 3.81-3.63(\mathrm{~m}, 14 \mathrm{H}), 3.57(\mathrm{dd}, J=$ 5.7, $3.6 \mathrm{~Hz}, 4 \mathrm{H}), 3.39(\mathrm{~s}, 6 \mathrm{H}), 2.00-1.76(\mathrm{~m}, 4 \mathrm{H}), 1.49$ (s, 6H) ppm. ${ }^{13} \mathrm{C}$ NMR (100 $\left.\mathrm{MHz}, \mathrm{CDCl}_{3}\right) \delta=159.58,159.37,152.57,141.82,138.20,135.64,133.58,129.77$, $129.70,129.01,127.42,117.42,117.29,114.91,110.77,71.95,70.88,70.68,70.61$, 69.70, 67.49, 67.28, 59.10, 51.22, 26.54, 25.79, 14.90 ppm.

N3-BDP5: N3-BDP (43.70 $\mathrm{mg}, \quad 0.01 \mathrm{mmol}, 1.0 \mathrm{eq})$ was reacted with 4-((2,5,8,11-tetraoxatridecan-13-yl)oxy)benzaldehyde (1.562 g, $0.50 \mathrm{mmol}, 50 \mathrm{eq})$ at $70{ }^{\circ} \mathrm{C}$ for $6.5 \mathrm{~h}$. The obtained residual oil was purified by silica gel column chromatography and eluted with $\mathrm{CH}_{2} \mathrm{Cl}_{2}$ and $\mathrm{MeOH}(v / v=100: 1)$ to give dark blue sticky solid (42.9 mg, $65 \%$ ). ${ }^{1} \mathrm{H}$ NMR (400 MHz, $\left.\mathrm{CDCl}_{3}\right) \delta=7.66-7.51(\mathrm{~m}, 6 \mathrm{H})$, $7.24-7.15(\mathrm{~m}, 4 \mathrm{H}), 6.97(\mathrm{dd}, J=20.1,8.7 \mathrm{~Hz}, 6 \mathrm{H}), 6.61(\mathrm{~s}, 2 \mathrm{H}), 4.24-4.14(\mathrm{~m}, 4 \mathrm{H})$, $4.05(\mathrm{t}, J=5.9 \mathrm{~Hz}, 2 \mathrm{H}), 3.93-3.83(\mathrm{~m}, 4 \mathrm{H}), 3.79-3.61(\mathrm{~m}, 22 \mathrm{H}), 3.55(\mathrm{dd}, J=5.6$, $3.7 \mathrm{~Hz}, 4 \mathrm{H}), 3.38(\mathrm{~s}, 6 \mathrm{H}), 1.98-1.76(\mathrm{~m}, 4 \mathrm{H}), 1.48$ (s, 6H) ppm. ${ }^{13} \mathrm{C}$ NMR (100 MHz, $\left.\mathrm{CDCl}_{3}\right) \delta=159.58,159.36,152.55,141.83,138.20,135.63,133.57,129.74,129.68$, 
$129.00,127.38,117.42,117.26,114.90,71.94,70.86,70.65,70.63,70.62,70.54$ $69.68,67.49,67.27,59.08,51.21,26.53,25.78,14.89$ ppm.

General procedure for Mito-BDP1-5. Under argon atmosphere, $\mathrm{N}_{3}$-BDP1-5 (0.3 mmol), compound 3 (237.1 mg, $0.6 \mathrm{mmol})$, sodium ascorbate $(60.0 \mathrm{mg}, 0.3 \mathrm{mmol})$ and $\mathrm{CuSO}_{4}(10.0 \mathrm{mg}, 0.06 \mathrm{mmol})$ were stirred in THF/water $(v / v=1: 1)$ at room temperature for overnight. The reaction was monitored using TLC. When the reaction completed, the solution was filtered by suction and the solvent was evaporated under reduced pressure to give the crude product. The residual solid was purified by silica gel column and eluted with $\mathrm{CH}_{2} \mathrm{Cl}_{2}$ and $\mathrm{MeOH}(\mathrm{v} / \mathrm{v}=10: 1)$ to give the respective desired product.
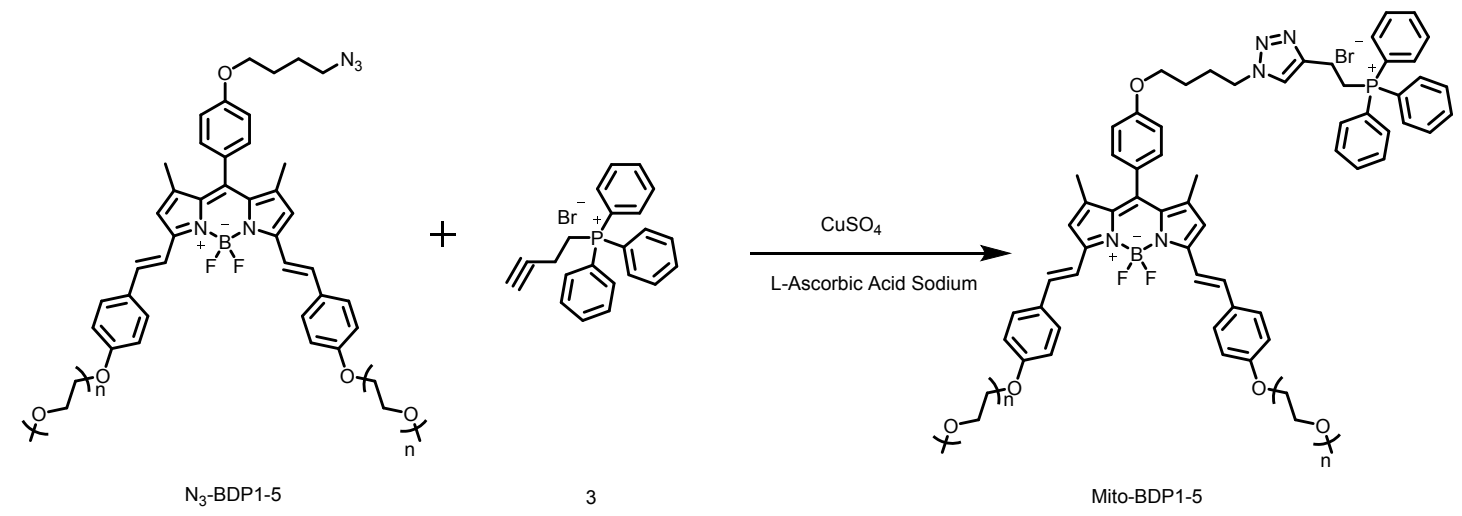

Scheme S3. Synthetic route for Mito-BDP1-5.

Mito-BDP1: N3-BDP1 (202.1 mg, $0.30 \mathrm{mmol}, 1.0 \mathrm{eq}$ ) was reacted with compound 3 (237.1 $\mathrm{mg}, 0.6 \mathrm{mmol}, 2.0 \mathrm{eq}$ ) until the material disappeared by TLC. The obtained crude product was purified by silica gel column with $\mathrm{CH}_{2} \mathrm{Cl}_{2}$ and $\mathrm{MeOH}$ to afford dark blue powder $(134.7 \mathrm{mg}, 42 \%) .{ }^{1} \mathrm{H}$ NMR $\left(400 \mathrm{MHz}, \mathrm{CDCl}_{3}\right) \delta=8.95(\mathrm{~s}, 1 \mathrm{H})$, $7.89(\mathrm{dd}, J=12.8,7.2 \mathrm{~Hz}, 6 \mathrm{H}), 7.79(\mathrm{t}, J=6.6 \mathrm{~Hz}, 3 \mathrm{H}), 7.70(\mathrm{td}, J=7.6,3.5 \mathrm{~Hz}, 6 \mathrm{H})$, 7.19 - 7.09 (m, 4H), 6.94 (ddd, $J=32.0,8.7,2.8 \mathrm{~Hz}, 6 \mathrm{H}), 6.58(\mathrm{~s}, 2 \mathrm{H}), 4.43$ (t, $J=7.3$ $\mathrm{Hz}, 2 \mathrm{H}), 4.28$ - $4.10(\mathrm{~m}, 2 \mathrm{H}), 4.07-3.96(\mathrm{~m}, 2 \mathrm{H}), 3.83(\mathrm{~s}, 6 \mathrm{H}), 3.19(\mathrm{td}, J=10.0,5.0$ $\mathrm{Hz}, 2 \mathrm{H}), 2.16(\mathrm{dt}, J=14.5,7.7 \mathrm{~Hz}, 3 \mathrm{H}), 1.93-1.77$ (m, 2H), 1.47 (d, $J=7.6 \mathrm{~Hz}, 7 \mathrm{H})$ ppm. ${ }^{13} \mathrm{C}-\mathrm{NMR}\left(100 \mathrm{MHz}, \mathrm{CDCl}_{3}\right) \delta=15.02,15.07,17.31,19.47,22.55,23.05$, 26.28, 27.09, 49.55, 50.05, 55.38, 67.06, 114.20, 114.90, 117.27, 117.43, 117.46, $118.29,118.57,124.82,127.81,128.93,128.95,129.70,129.86,129.91,130.49$, 
$130.52,130.61,133.51,133.75,133.85,134.31,134.43,135.12,135.15,138.51$, $138.57,140.75,140.83,144.31,144.49,152.46,152.53,159.25,160.06$ ppm.

Mito-BDP2. N-BDP2 (228.5 mg, $0.30 \mathrm{mmol}, 1.0 \mathrm{eq})$ was reacted with compound 3 (237.1 mg, $0.6 \mathrm{mmol}, 2.0 \mathrm{eq}$ ) until the starting material disappeared as monitored by TLC. The obtained crude product was purified by silica gel column with $\mathrm{CH}_{2} \mathrm{Cl}_{2}$ and $\mathrm{MeOH}$ to afford dark blue powder (156.2 mg, 45\%). ${ }^{1} \mathrm{H}$ NMR $\left(400 \mathrm{MHz}, \mathrm{CDCl}_{3}\right) \delta=$ $9.00(\mathrm{~s}, 1 \mathrm{H}), 7.96-7.84(\mathrm{~m}, 6 \mathrm{H}), 7.80(\mathrm{td}, J=7.3,1.7 \mathrm{~Hz}, 3 \mathrm{H}), 7.71(\mathrm{td}, J=7.6,3.5$ $\mathrm{Hz}, 6 \mathrm{H}), 7.64$ - $7.54(\mathrm{~m}, 6 \mathrm{H}), 7.24$ - $7.13(\mathrm{~m}, 3 \mathrm{H}), 7.06$ - $6.90(\mathrm{~m}, 6 \mathrm{H}), 6.60(\mathrm{~s}, 2 \mathrm{H})$, $4.44(\mathrm{t}, J=7.2 \mathrm{~Hz}, 2 \mathrm{H}), 4.21-4.14(\mathrm{~m}, 4 \mathrm{H}), 4.04(\mathrm{t}, J=5.9 \mathrm{~Hz}, 2 \mathrm{H}), 3.85$ - $3.75(\mathrm{~m}$, 4H), $3.48(\mathrm{~s}, 6 \mathrm{H}), 3.19$ (q, $J=9.5 \mathrm{~Hz}, 2 \mathrm{H}), 2.24-2.11(\mathrm{~m}, 2 \mathrm{H}), 1.93-1.79(\mathrm{~m}, 2 \mathrm{H})$, $1.48(\mathrm{~s}, 6 \mathrm{H}) \mathrm{ppm} .{ }^{13} \mathrm{C} \mathrm{NMR}\left(100 \mathrm{MHz}, \mathrm{CDCl}_{3}\right) \delta=159.49,159.36,152.49,152.48$, $147.44,144.57,144.39,142.00,135.51,135.14,135.11,133.86,133.76,130.65$, 130.62 , 130.49, 129.80, 129.65, 129.40, 129.00, 127.20, 124.86, 118.32, 117.46, $117.38,117.37,114.99,114.96,114.88,70.97,67.32$, 59.30, 50.07, 27.07, 26.26, 23.03, 22.54, 19.54, 19.52, $14.95 \mathrm{ppm}$.

Mito-BDP3. N3-BDP3 (254.9 mg, $0.30 \mathrm{mmol}, 1.0 \mathrm{eq}$ ) was reacted with compound 3 (237.1 mg, $0.6 \mathrm{mmol}, 2.0 \mathrm{eq}$ ) until the starting material disappeared as monitored by TLC. The obtained crude product was purified by silica gel column with $\mathrm{CH}_{2} \mathrm{Cl}_{2}$ and $\mathrm{MeOH}$ to afford dark blue powder (179.3 mg, 48\%). ${ }^{1} \mathrm{H}$ NMR $\left(400 \mathrm{MHz}, \mathrm{CDCl}_{3}\right) \delta=$ $8.89(\mathrm{~s}, 1 \mathrm{H}), 7.98$ - $7.77(\mathrm{~m}, 6 \mathrm{H}), 7.76$ - $7.66(\mathrm{~m}, 3 \mathrm{H}), 7.66$ - $7.46(\mathrm{~m}, 6 \mathrm{H}), 7.24-7.10$ (m, 4H), $6.97(\mathrm{dd}, J=20.9,8.5 \mathrm{~Hz}, 6 \mathrm{H}), 6.60(\mathrm{~s}, 2 \mathrm{H}), 4.44(\mathrm{t}, J=7.1 \mathrm{~Hz}, 2 \mathrm{H}), 4.24$ $4.16(\mathrm{~m}, 4 \mathrm{H}), 4.05(\mathrm{t}, J=5.9 \mathrm{~Hz}, 2 \mathrm{H}), 3.89$ (t, $J=4.8 \mathrm{~Hz}, 4 \mathrm{H}), 3.79-3.71(\mathrm{~m}, 4 \mathrm{H})$, $3.65-3.55(\mathrm{~m}, 4 \mathrm{H}), 3.41$ (s, 6H), $3.30-3.10(\mathrm{~m}, 2 \mathrm{H}), 2.17$ (p, J=7.2 Hz, 2H), 1.84 (q, $J=6.9,6.2 \mathrm{~Hz}, 2 \mathrm{H}), 1.48(\mathrm{~s}, 6 \mathrm{H}) \mathrm{ppm} .{ }^{13} \mathrm{C}-\mathrm{NMR}\left(100 \mathrm{MHz}, \mathrm{CDCl}_{3}\right) \delta=159.50$, 159.36, 152.50, 152.48, 142.01, 141.98, 138.42, 135.53, 135.21, 135.18, 133.86, $133.76,133.60,130.65,130.52,129.75,129.65,129.06,129.00,127.20,125.28$, 124.84, 118.20, 117.46, 117.39, 117.35, 115.05, 115.02, 114.90, 71.95, 70.79, 69.71, $67.47,67.07,59.14,50.10,27.03,26.25,23.31,22.81,19.45,14.95$ ppm.

Mito-BDP4. N3-BDP4 (281.4 mg, $0.30 \mathrm{mmol}, 1.0 \mathrm{eq})$ was reacted with compound 3 (237.1 mg, $0.60 \mathrm{mmol}, 2.0 \mathrm{eq}$ ) until the starting material disappeared as monitored by 
TLC. The obtained crude product was purified by silica gel column with $\mathrm{CH}_{2} \mathrm{Cl}_{2}$ and $\mathrm{MeOH}$ to give dark blue waxy solid (204.0 mg, 51\%). ${ }^{1} \mathrm{H}$ NMR (400 MHz, $\mathrm{CDCl}_{3}$ ) $\delta$ $=8.99(\mathrm{~s}, 1 \mathrm{H}), 7.95-7.85(\mathrm{~m}, 6 \mathrm{H}), 7.81(\mathrm{td}, J=7.4,1.6 \mathrm{~Hz}, 3 \mathrm{H}), 7.76-7.67(\mathrm{~m}, 6 \mathrm{H})$, 7.65 - $7.52(\mathrm{~m}, 6 \mathrm{H}), 7.24$ - $7.14(\mathrm{~m}, 4 \mathrm{H}), 6.97(\mathrm{dd}, J=21.5,8.6 \mathrm{~Hz}, 6 \mathrm{H}), 6.60(\mathrm{~s}, 2 \mathrm{H})$, $4.43(\mathrm{t}, J=7.1 \mathrm{~Hz}, 2 \mathrm{H}), 4.19(\mathrm{t}, J=4.8 \mathrm{~Hz}, 4 \mathrm{H}), 4.06$ (t, $J=5.9 \mathrm{~Hz}, 2 \mathrm{H}), 3.94-3.86$ (m, 4H), $3.81-3.64(\mathrm{~m}, 14 \mathrm{H}), 3.57(\mathrm{dd}, J=5.7,3.7 \mathrm{~Hz}, 4 \mathrm{H}), 3.39$ (s, 6H), 3.20 (q, $J=$ $9.2 \mathrm{~Hz}, 2 \mathrm{H}), 2.18(\mathrm{t}, J=7.2 \mathrm{~Hz}, 2 \mathrm{H}), 1.86(\mathrm{t}, J=7.1 \mathrm{~Hz}, 2 \mathrm{H}), 1.70(\mathrm{~s}, 6 \mathrm{H}) \mathrm{ppm} .{ }^{13} \mathrm{C}$ NMR (100 MHz, $\left.\mathrm{CDCl}_{3}\right) \delta=159.52,159.36,152.47,144.40,144.23,142.00,138.42$, $135.54,135.19,135.16,133.84,133.74,133.59,130.63,130.51,129.72,129.64$, $128.99,127.18,124.80,118.21,117.39$, 117.36, 117.31, 115.01, 114.90, 77.40, 77.09, $76.77,71.92,70.85,70.65,70.57,69.69,67.47,67.07,59.08,50.75,50.07,27.03$, $26.25,23.22,22.72,19.46,14.95 \mathrm{ppm}$.

Mito-BDP5. N- N-BP5 (307.8 mg, $0.30 \mathrm{mmol}, 1.0 \mathrm{eq})$ was reacted with compound 3 (237.1 $\mathrm{mg}, 0.6 \mathrm{mmol}, 2.0 \mathrm{eq}$ ) until the starting material disappeared as monitored by TLC. The obtained crude product was purified by silica gel column with $\mathrm{CH}_{2} \mathrm{Cl}_{2}$ and $\mathrm{MeOH}$ to afford dark blue waxy solid (183.3 mg, 43\%). ${ }^{1} \mathrm{H}$ NMR (400 MHz, $\left.\mathrm{CDCl}_{3}\right) \delta$ $=8.97(\mathrm{~d}, J=4.4 \mathrm{~Hz}, 1 \mathrm{H}), 7.88(\mathrm{dd}, J=12.9,7.4 \mathrm{~Hz}, 6 \mathrm{H}), 7.79(\mathrm{td}, J=7.2,1.5 \mathrm{~Hz}$, 3H), $7.71(\mathrm{dd}, J=7.7,3.3 \mathrm{~Hz}, 6 \mathrm{H}), 7.62-7.53(\mathrm{~m}, 6 \mathrm{H}), 7.23$ - $7.12(\mathrm{~m}, 4 \mathrm{H}), 6.96(\mathrm{dd}$, $J=22.1,8.7 \mathrm{~Hz}, 6 \mathrm{H}), 6.59(\mathrm{~s}, 2 \mathrm{H}), 4.42(\mathrm{t}, J=7.0 \mathrm{~Hz}, 2 \mathrm{H}), 4.17$ (t, $J=5.0 \mathrm{~Hz}, 4 \mathrm{H})$, $4.04(\mathrm{t}, J=6.1 \mathrm{~Hz}, 2 \mathrm{H}), 3.91-3.85(\mathrm{~m}, 4 \mathrm{H}), 3.78-3.60(\mathrm{~m}, 22 \mathrm{H}), 3.59-3.50(\mathrm{~m}$, $4 \mathrm{H}), 3.37(\mathrm{~s}, 6 \mathrm{H}), 3.23-3.14(\mathrm{~m}, 2 \mathrm{H}), 2.22-2.09(\mathrm{~m}, 2 \mathrm{H}), 1.84(\mathrm{td}, J=12.5,11.9,5.9$ $\mathrm{Hz}, 2 \mathrm{H}) .1 .48$ (s, 6H) ppm. ${ }^{13} \mathrm{C} \mathrm{NMR}\left(100 \mathrm{MHz}, \mathrm{CDCl}_{3}\right) \delta=159.53,159.35,156.01$, $152.45,144.40,144.22,142.00,138.41,135.53,135.18,135.15,133.87,133.83$, $133.77,133.59$, 130.63, 130.58, 130.50, 129.71, 129.63, 128.98, 127.17, 124.98, 121.56, 118.39, 118.20, 117.38, 117.35, 117.30, 115.01, 114.89, 71.92, 70.84, 70.62, $70.60,70.51,69.68,67.48,67.06,59.07,50.07,27.02,26.25,23.36,22.86,19.52$, $14.95 \mathrm{ppm}$. 


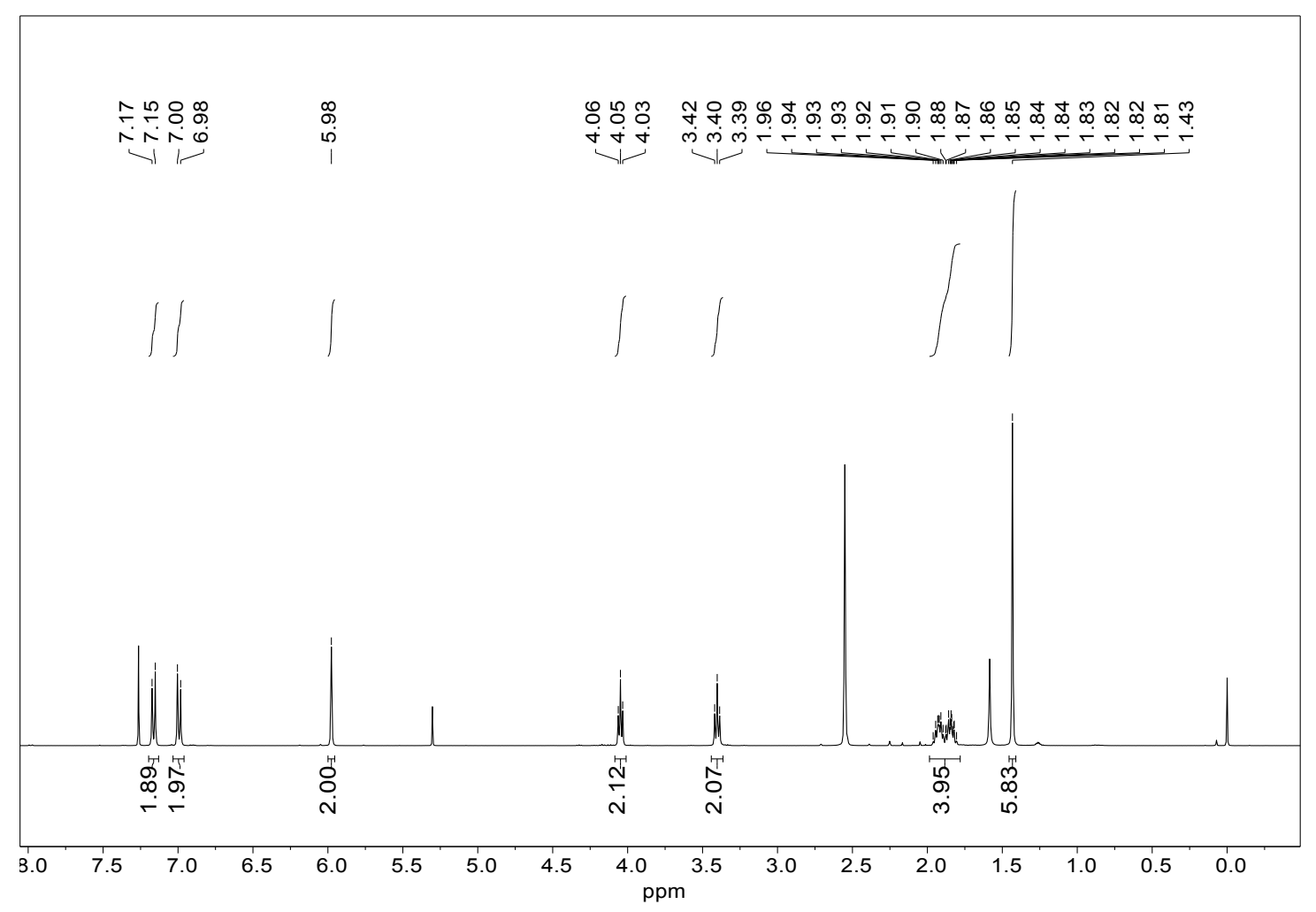

Figure S1. ${ }^{1} \mathrm{H}$ NMR spectrum of $\mathbf{N}_{\mathbf{3}}$-BDP in $d$-chloroform.

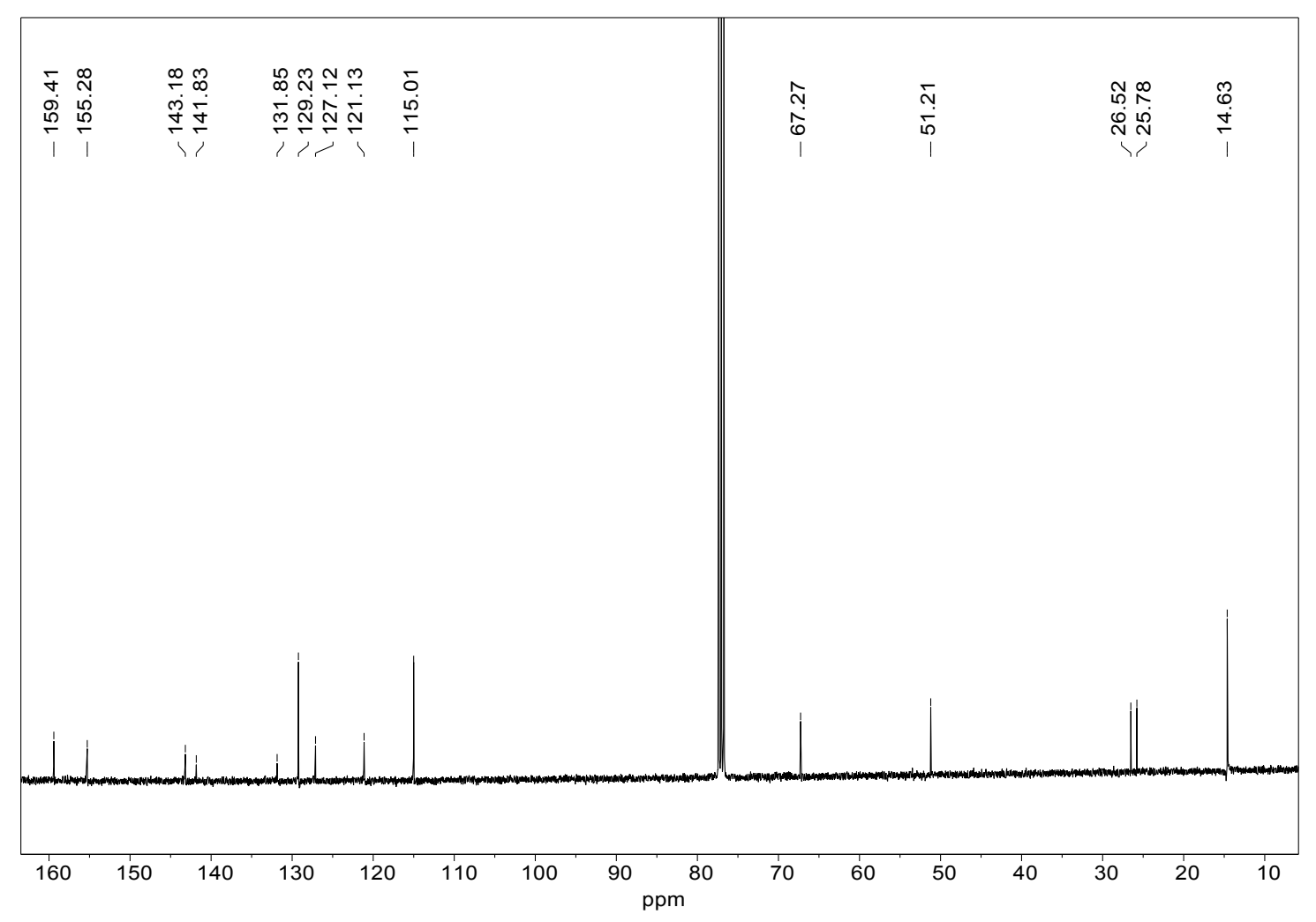

Figure S2. ${ }^{13} \mathrm{C}$ NMR spectrum of $\mathbf{N}_{\mathbf{3}}$-BDP in $d$-chloroform. 


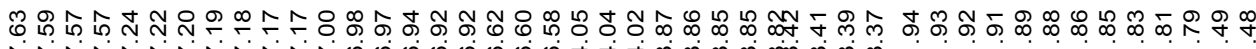

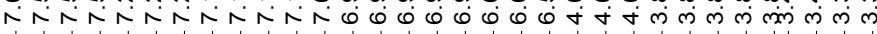
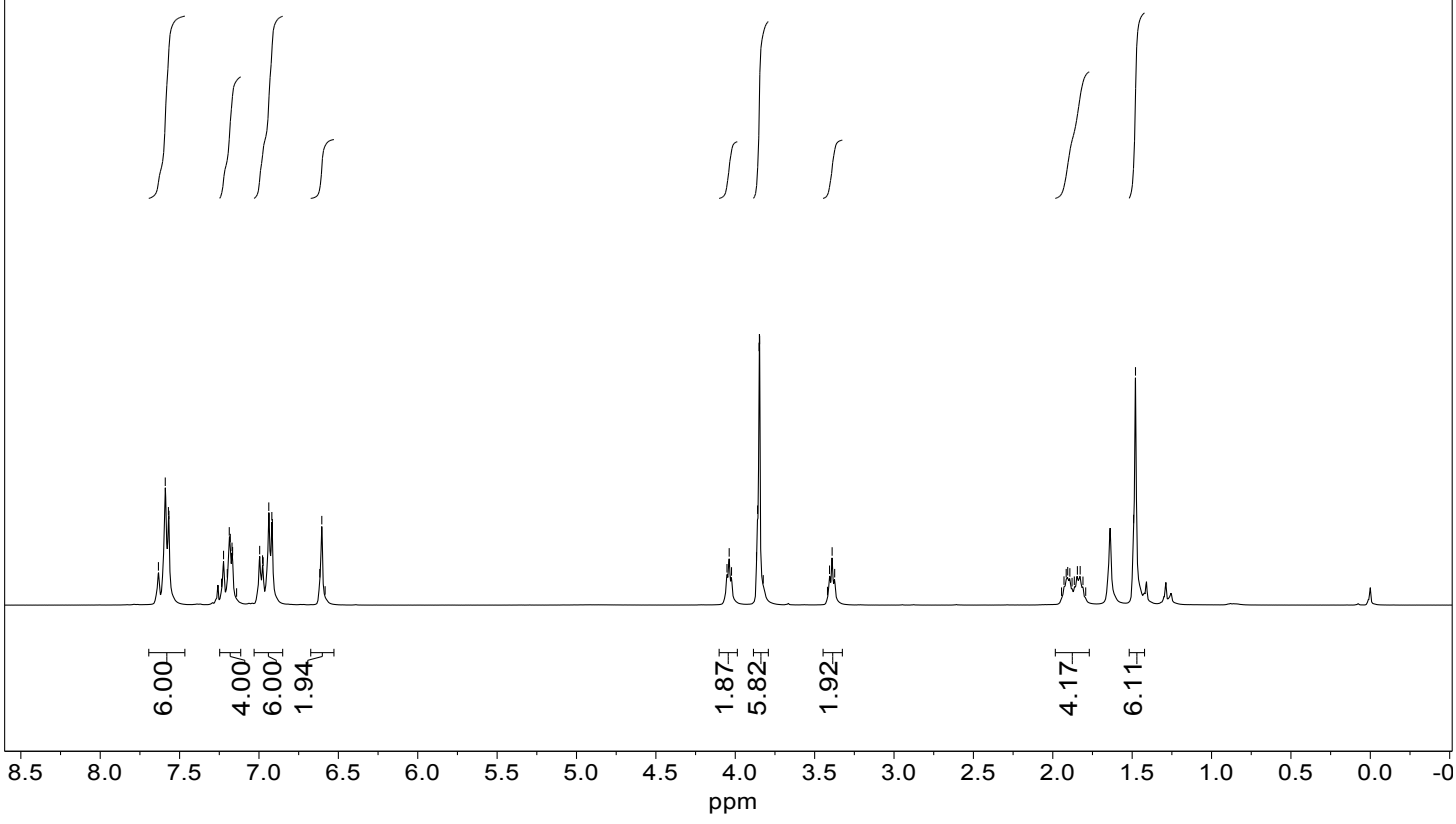

Figure S3. ${ }^{1} \mathrm{H}$ NMR spectrum of $\mathbf{N}_{\mathbf{3}}$-BDP1 in $d$-chloroform.

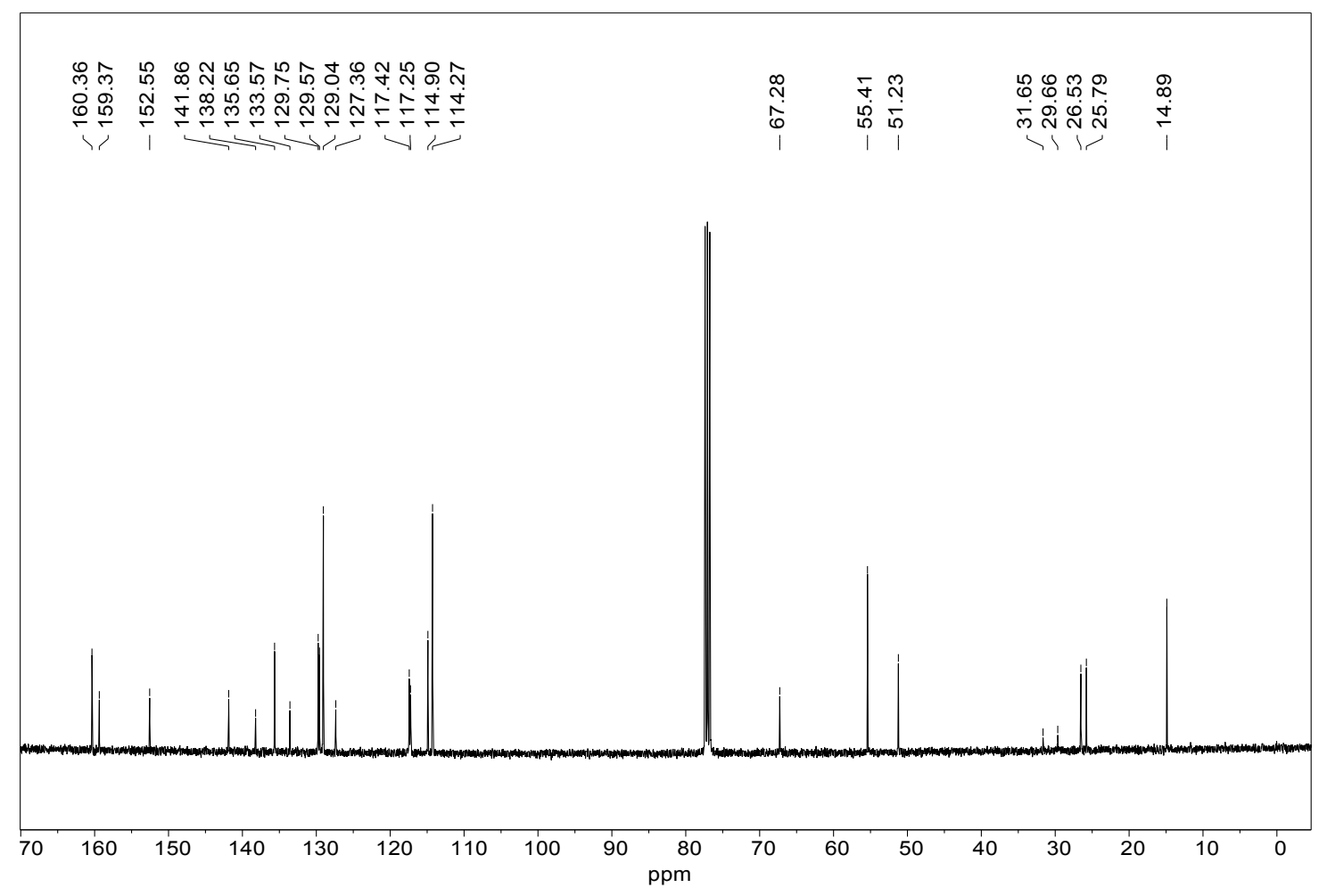

Figure S4. ${ }^{13} \mathrm{C}$ NMR spectrum of $\mathbf{N}_{\mathbf{3}}$-BDP1 in $d$-chloroform. 


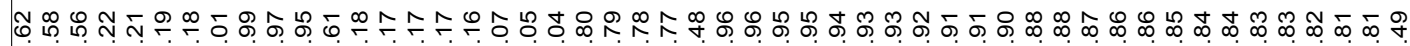

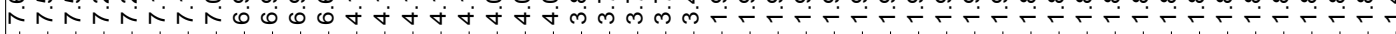

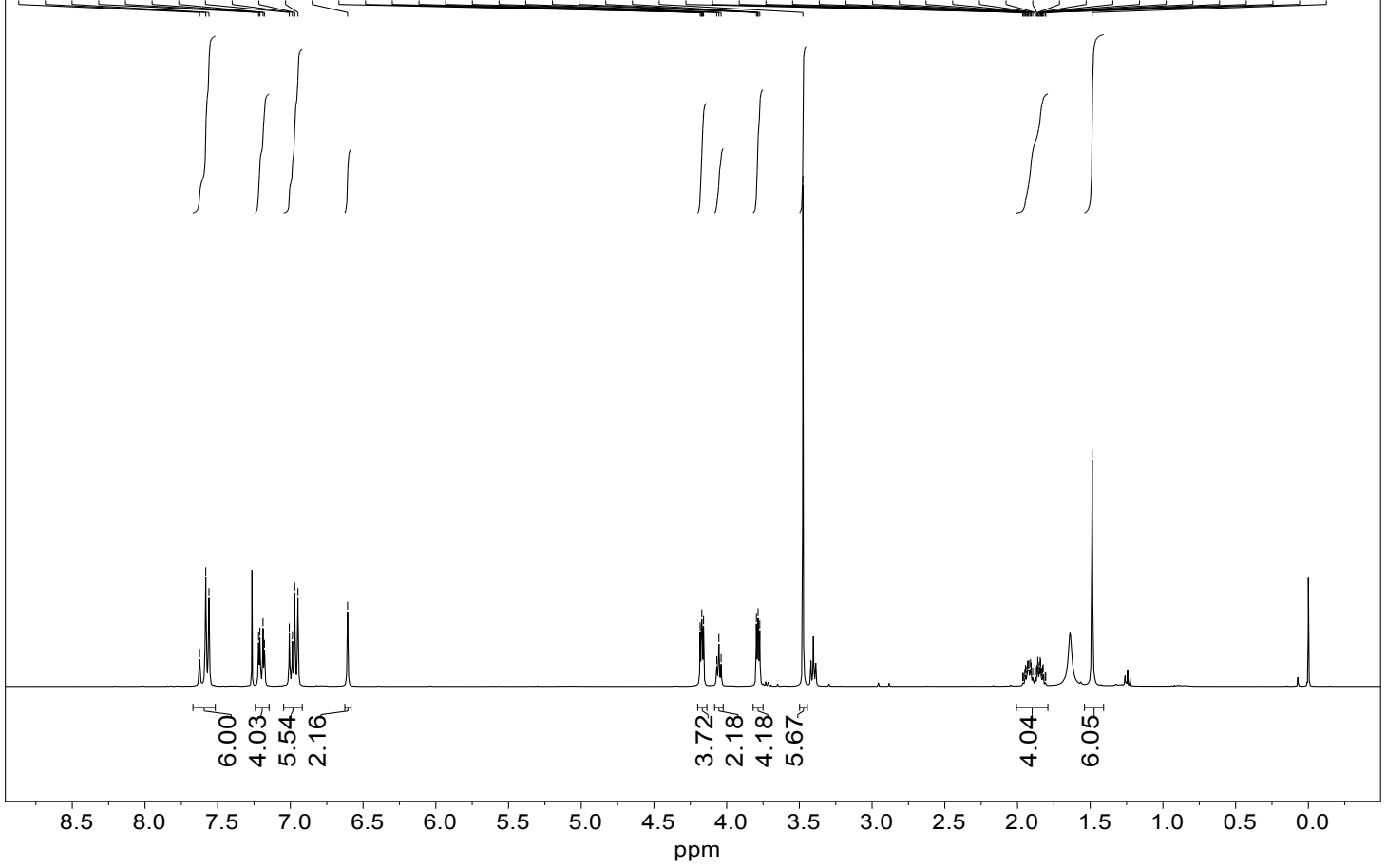

Figure S5. ${ }^{1} \mathrm{H}$ NMR spectrum of $\mathbf{N}_{\mathbf{3}}$-BDP2 in $d$-chloroform.

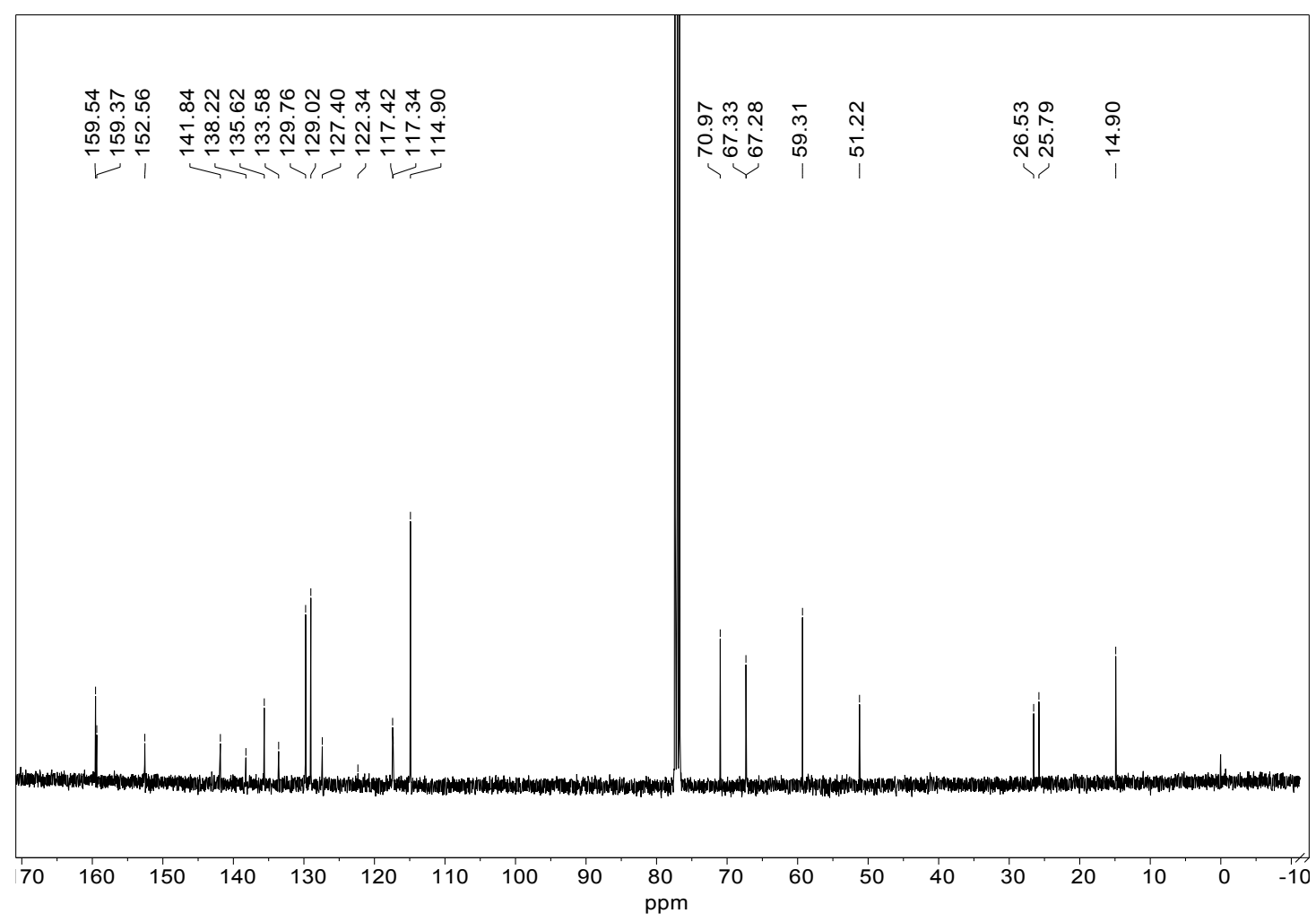

Figure S6. ${ }^{13} \mathrm{C}$ NMR spectrum of $\mathbf{N}_{\mathbf{3}}$-BDP2 in $d$-chloroform. 


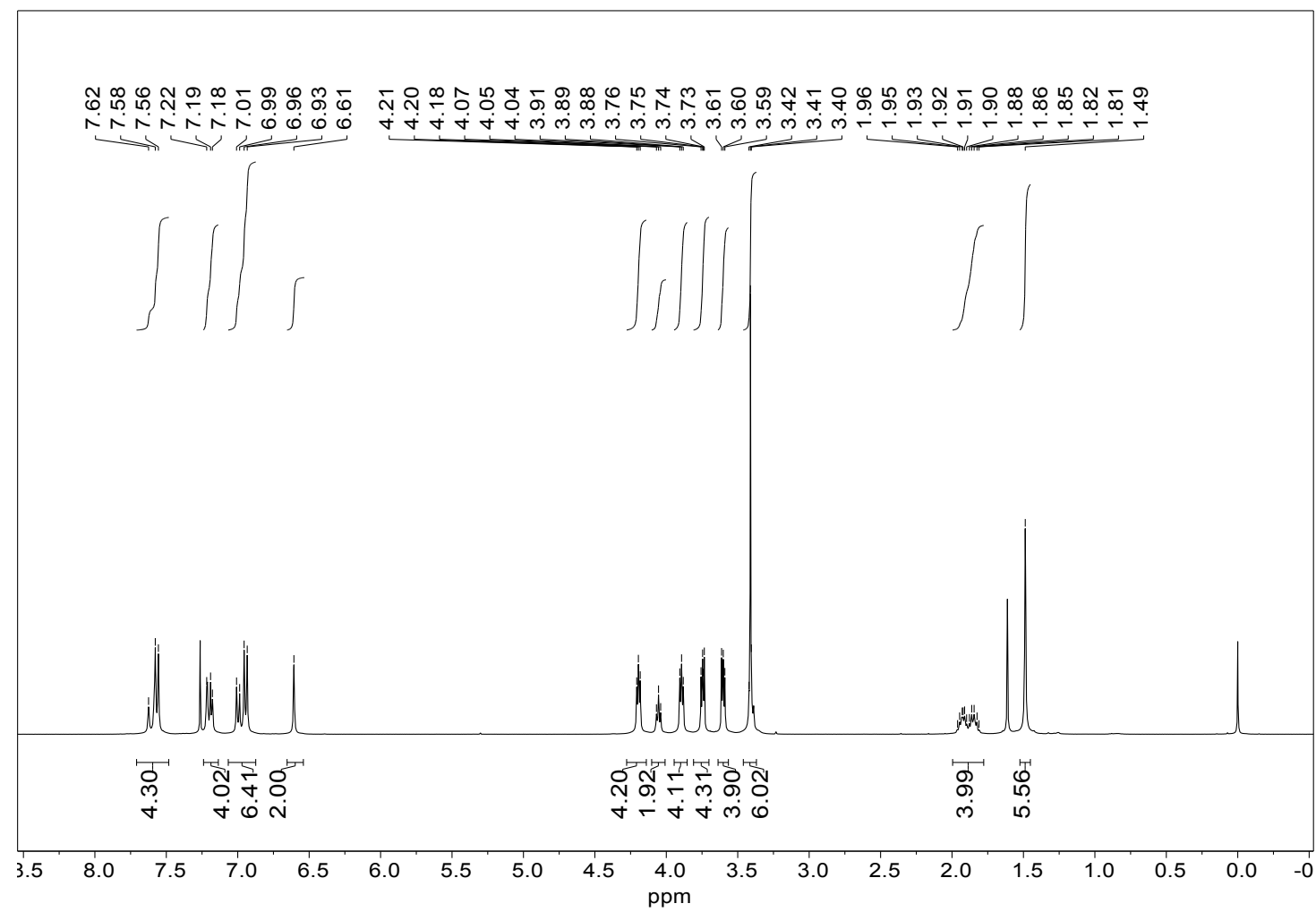

Figure S7. ${ }^{1} \mathrm{H}$ NMR spectrum of $\mathbf{N}_{\mathbf{3}}$-BDP3 in $d$-chloroform.

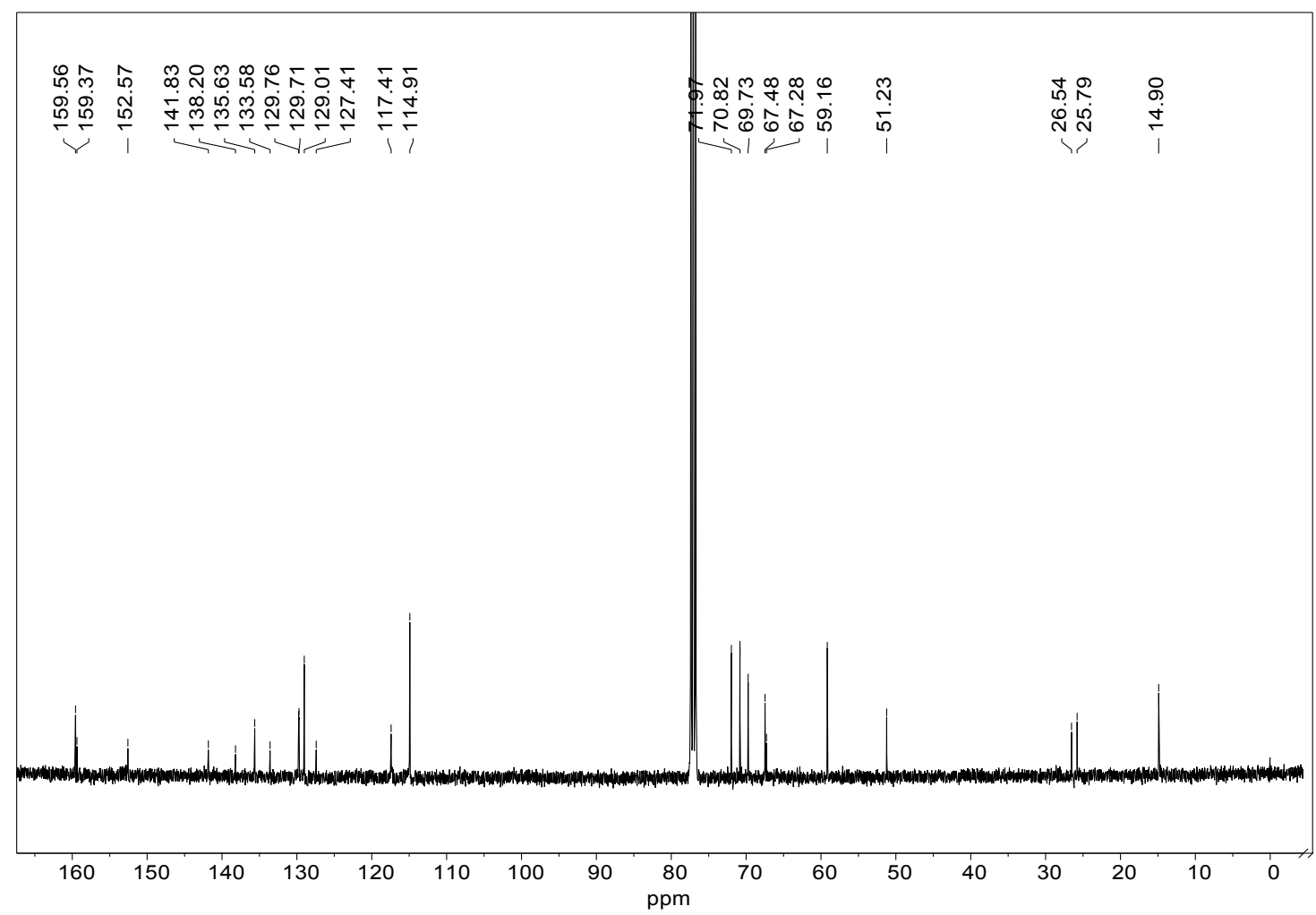

Figure S8. ${ }^{13} \mathrm{C}$ NMR spectrum of $\mathbf{N}_{\mathbf{3}}$-BDP3 in $d$-chloroform. 


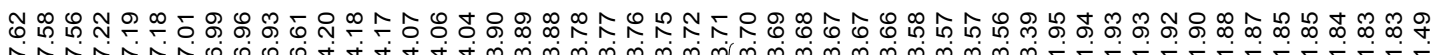

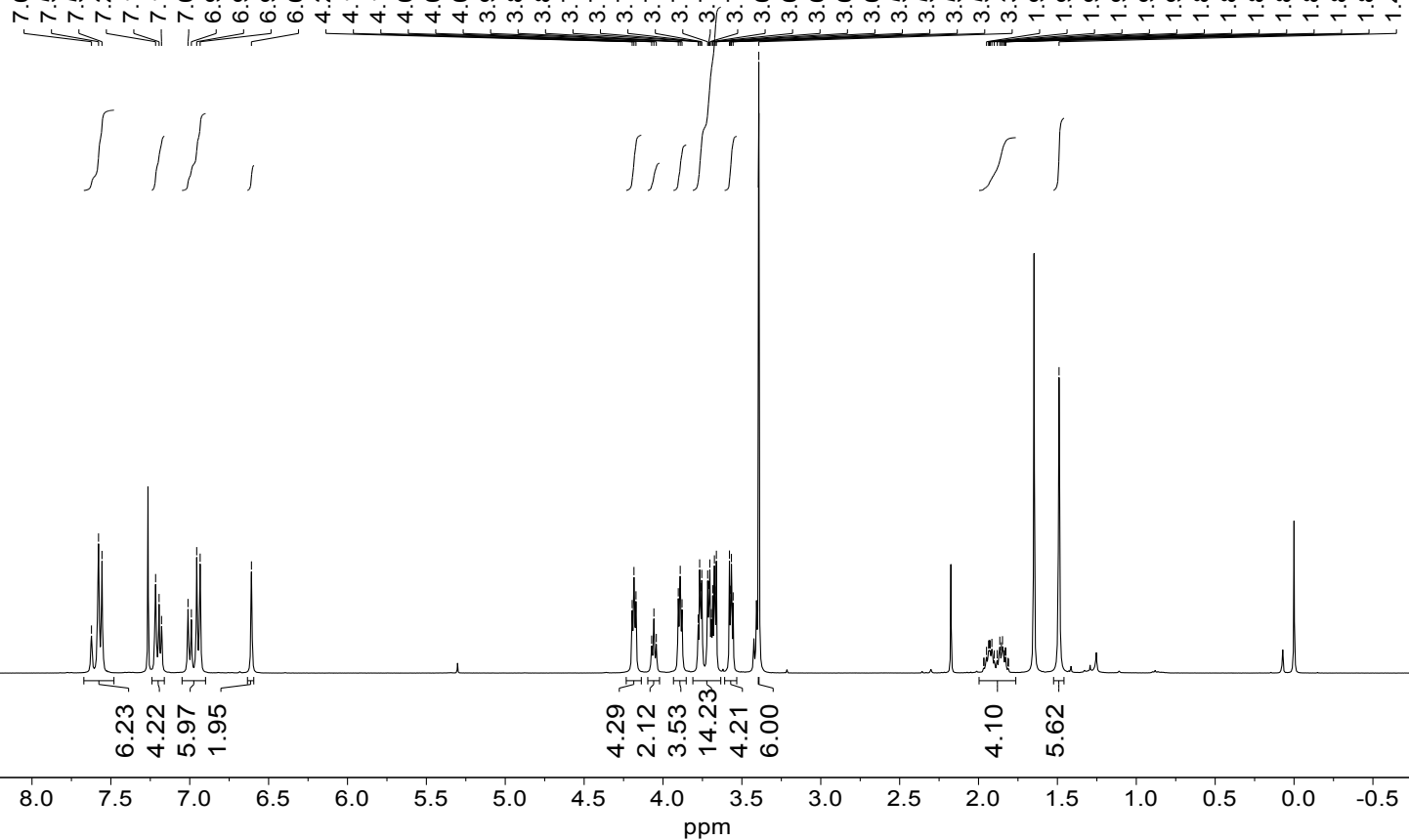

Figure S9. ${ }^{1} \mathrm{H}$ NMR spectrum of $\mathbf{N}_{\mathbf{3}}$-BDP4 in $d$-chloroform.

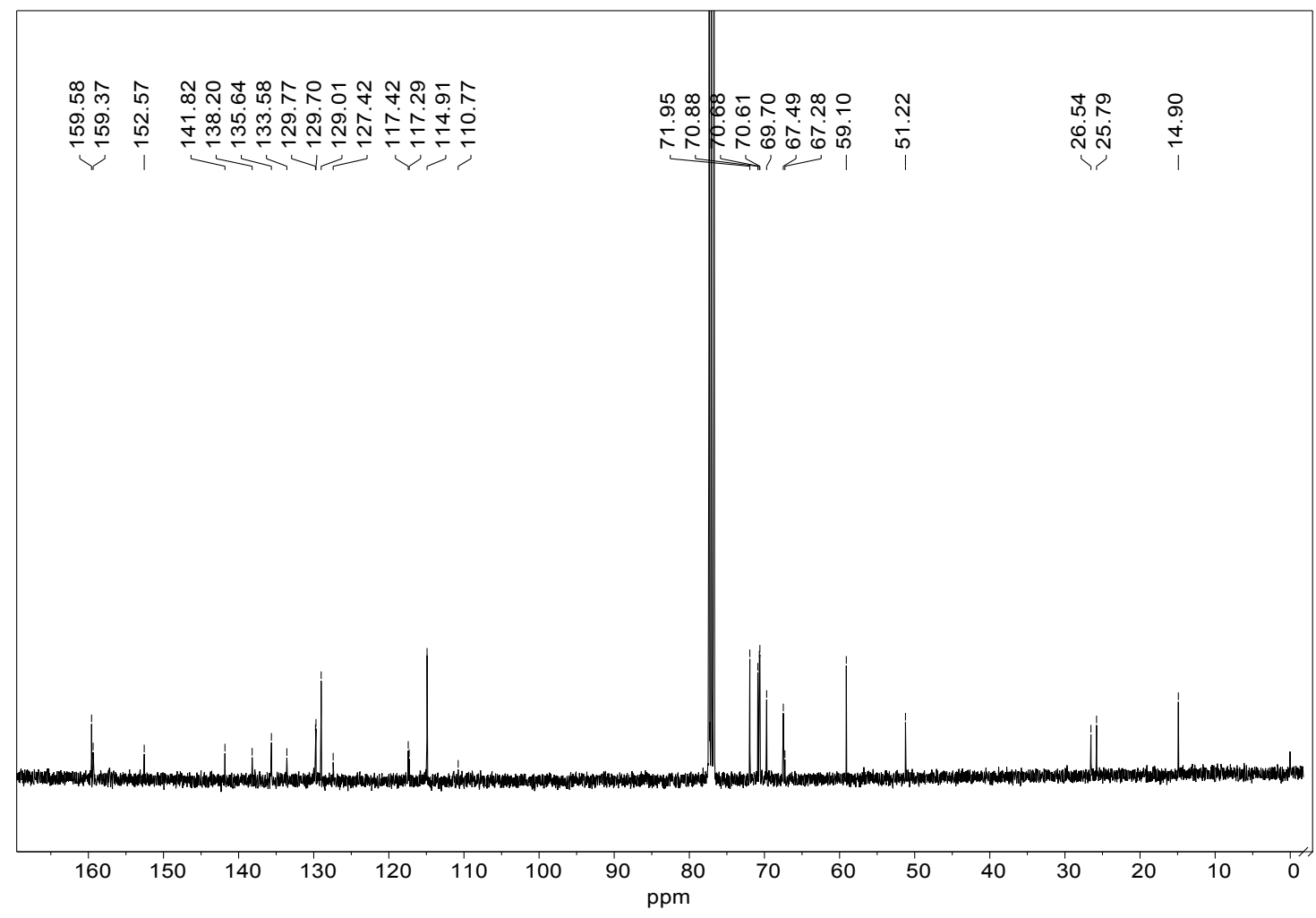

Figure S10. ${ }^{13} \mathrm{C}$ NMR spectrum of $\mathbf{N}_{3}$-BDP4 in $d$-chloroform. 


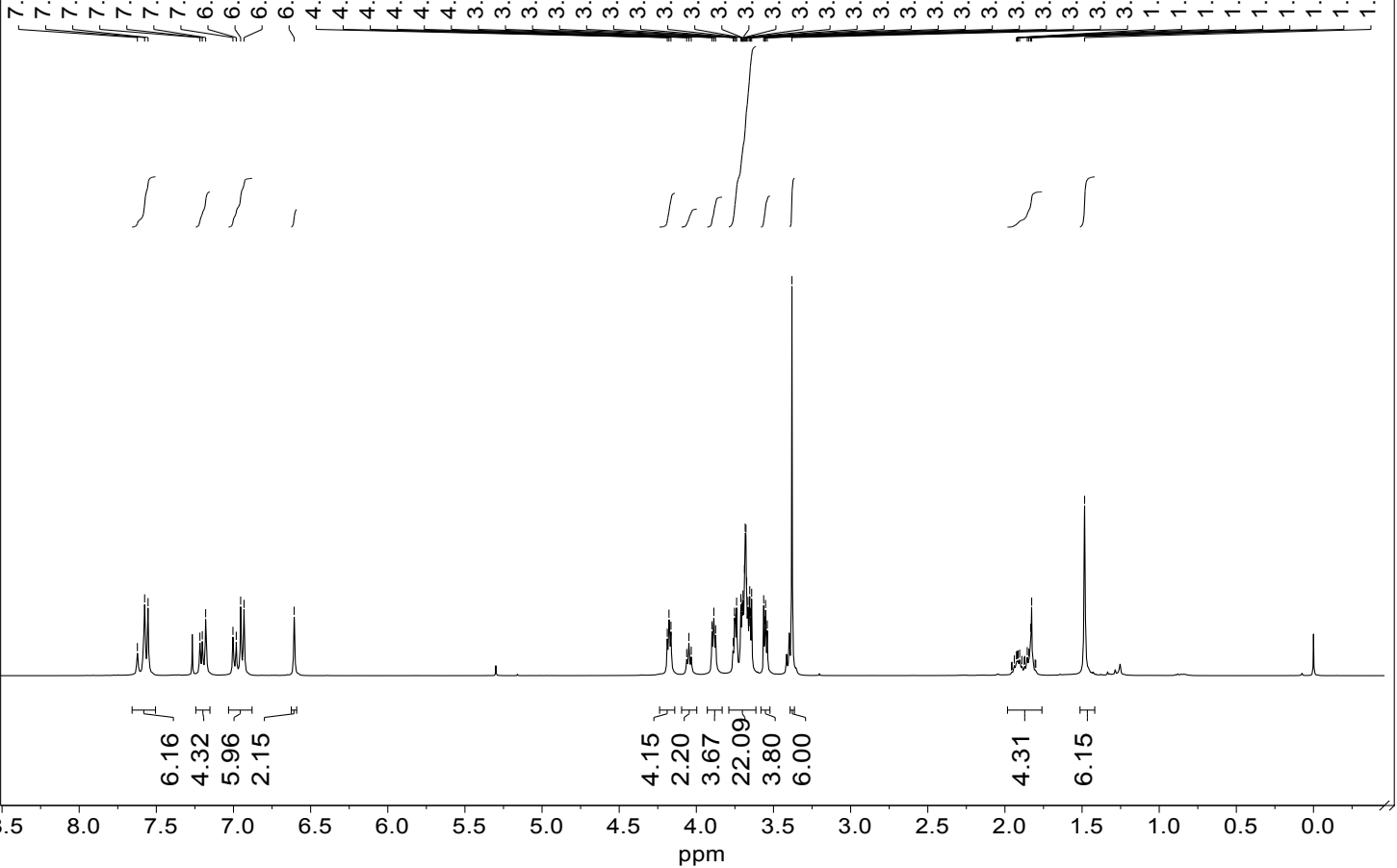

Figure S11. ${ }^{1} \mathrm{H}$ NMR spectrum of $\mathbf{N}_{3}$-BDP5 in $d$-chloroform.

舟员

官

re

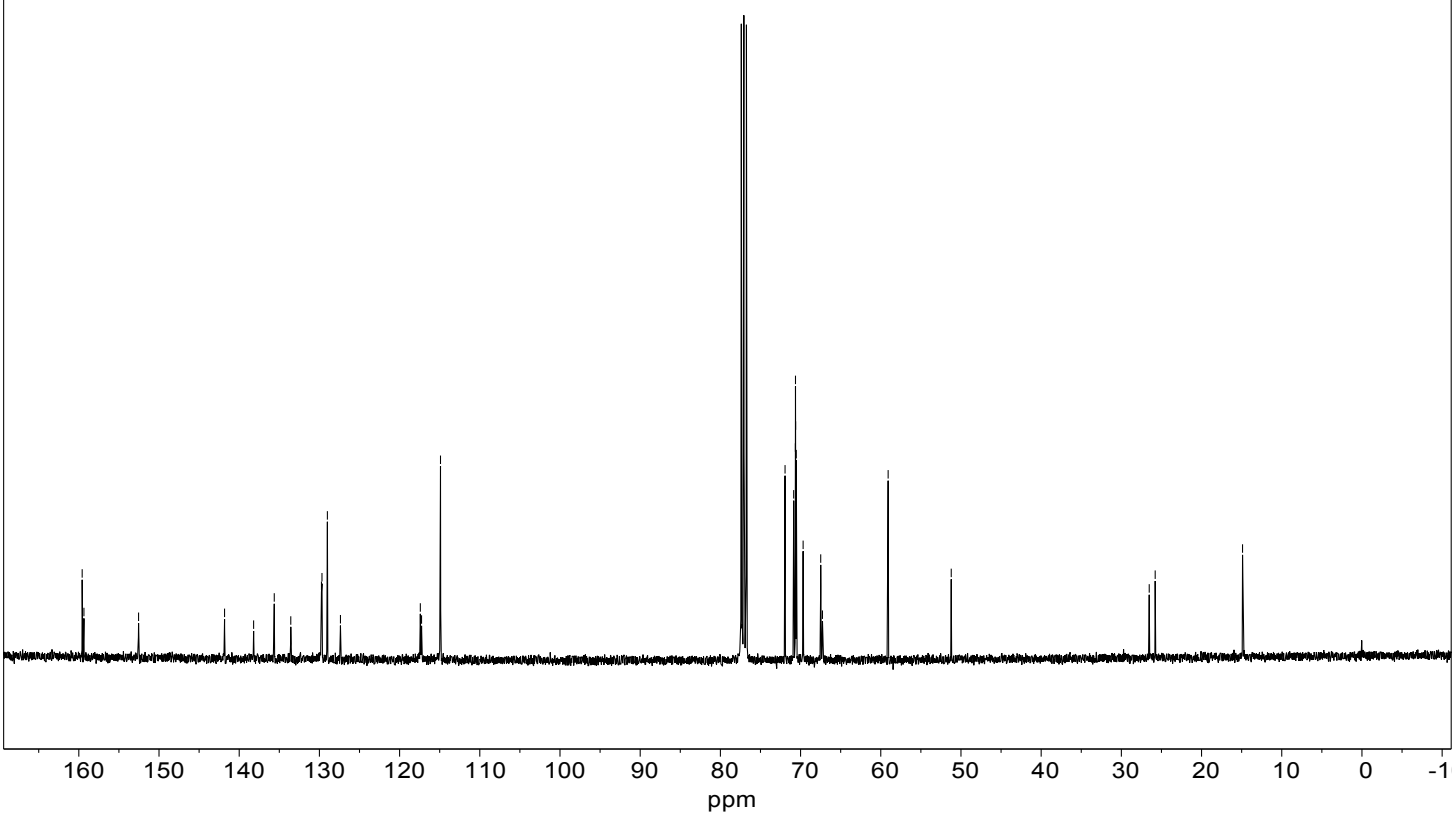

Figure S12. ${ }^{13} \mathrm{C}$ NMR spectrum of $\mathbf{N}_{3}$-BDP5 in $d$-chloroform. 


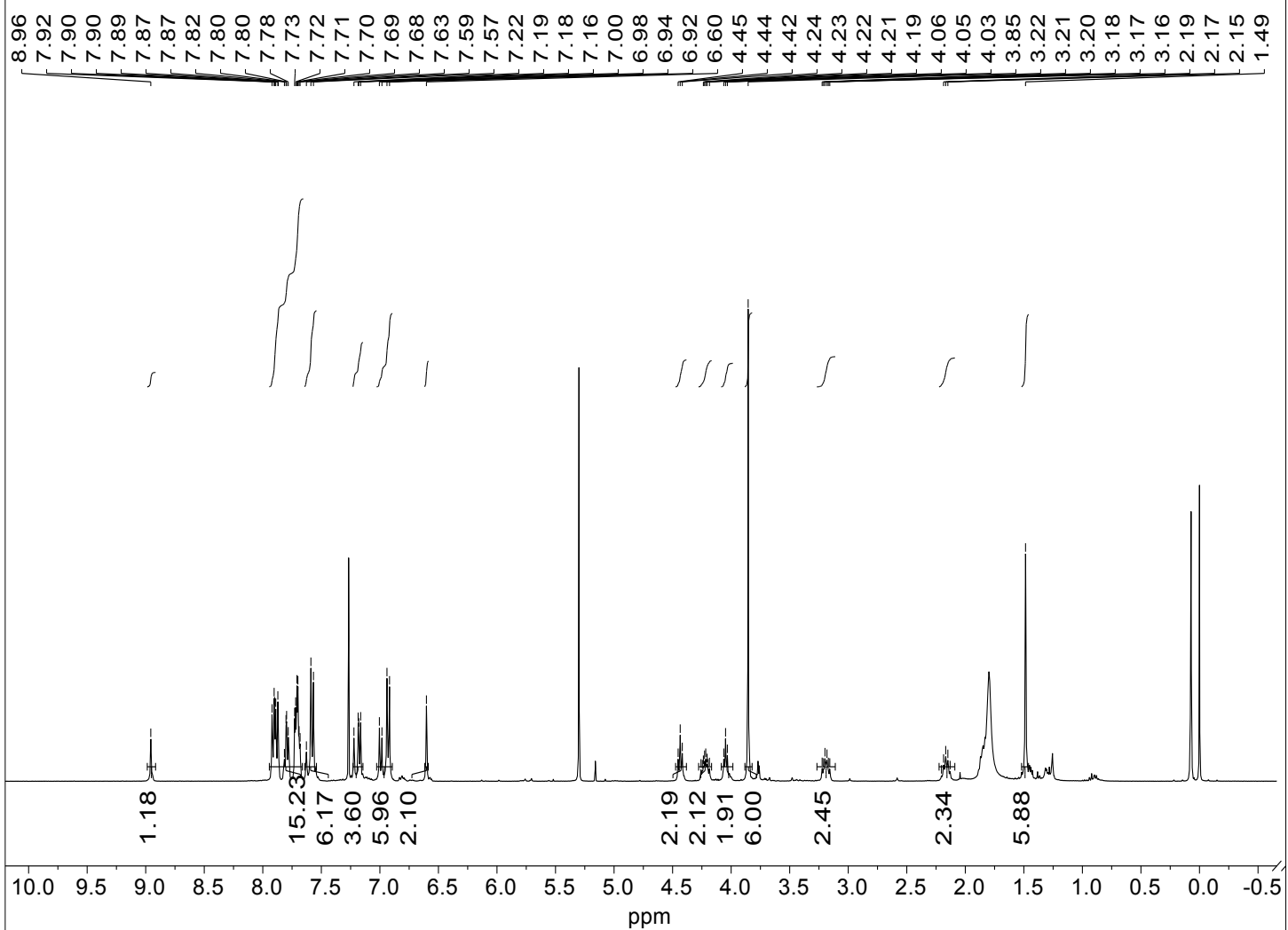

Figure S13. ${ }^{1} \mathrm{H}$ NMR spectrum of Mito-BDP1 in $d$-chloroform.

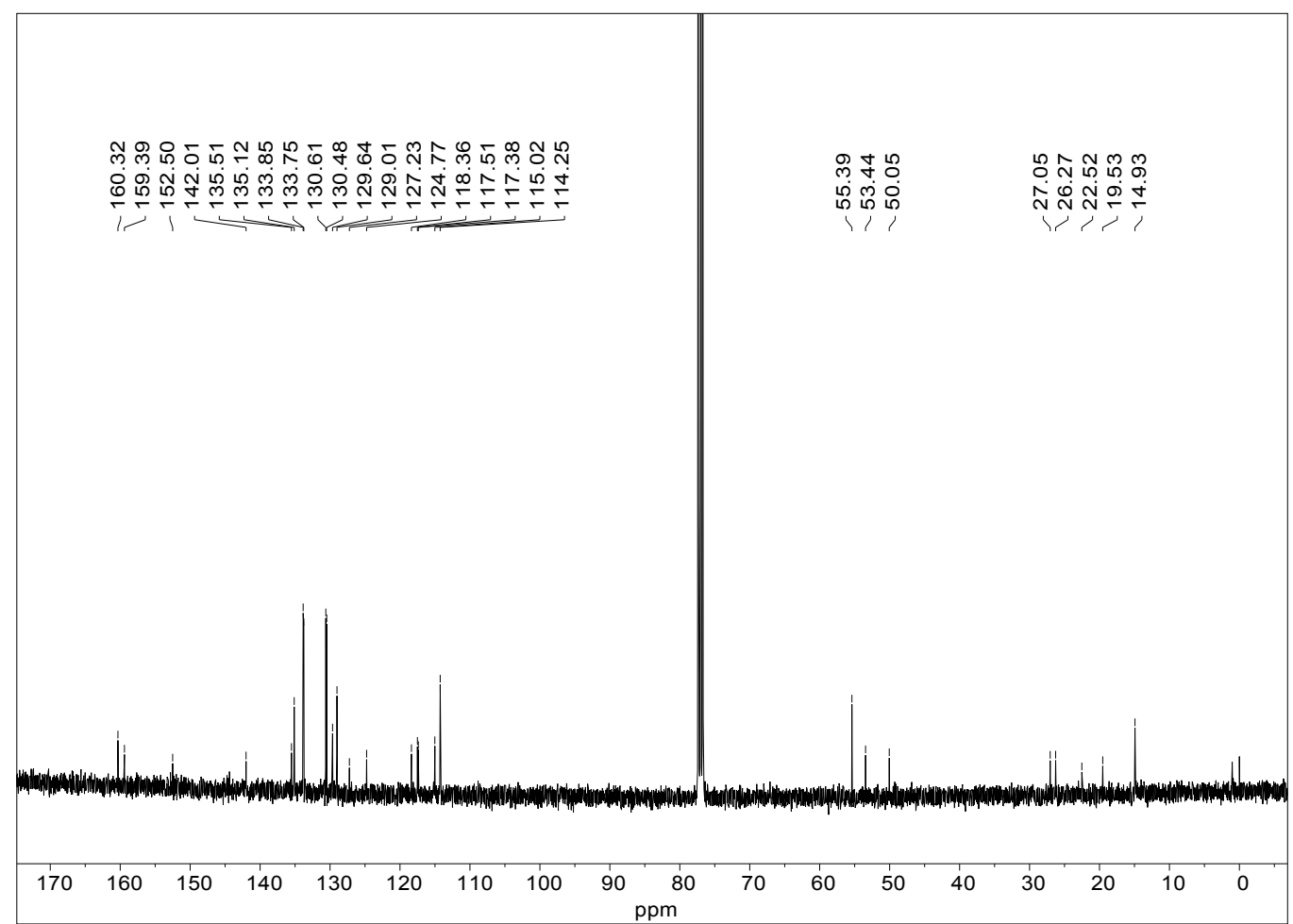

Figure S14. ${ }^{13} \mathrm{C}$ NMR spectrum of Mito-BDP1 in $d$-chloroform. 


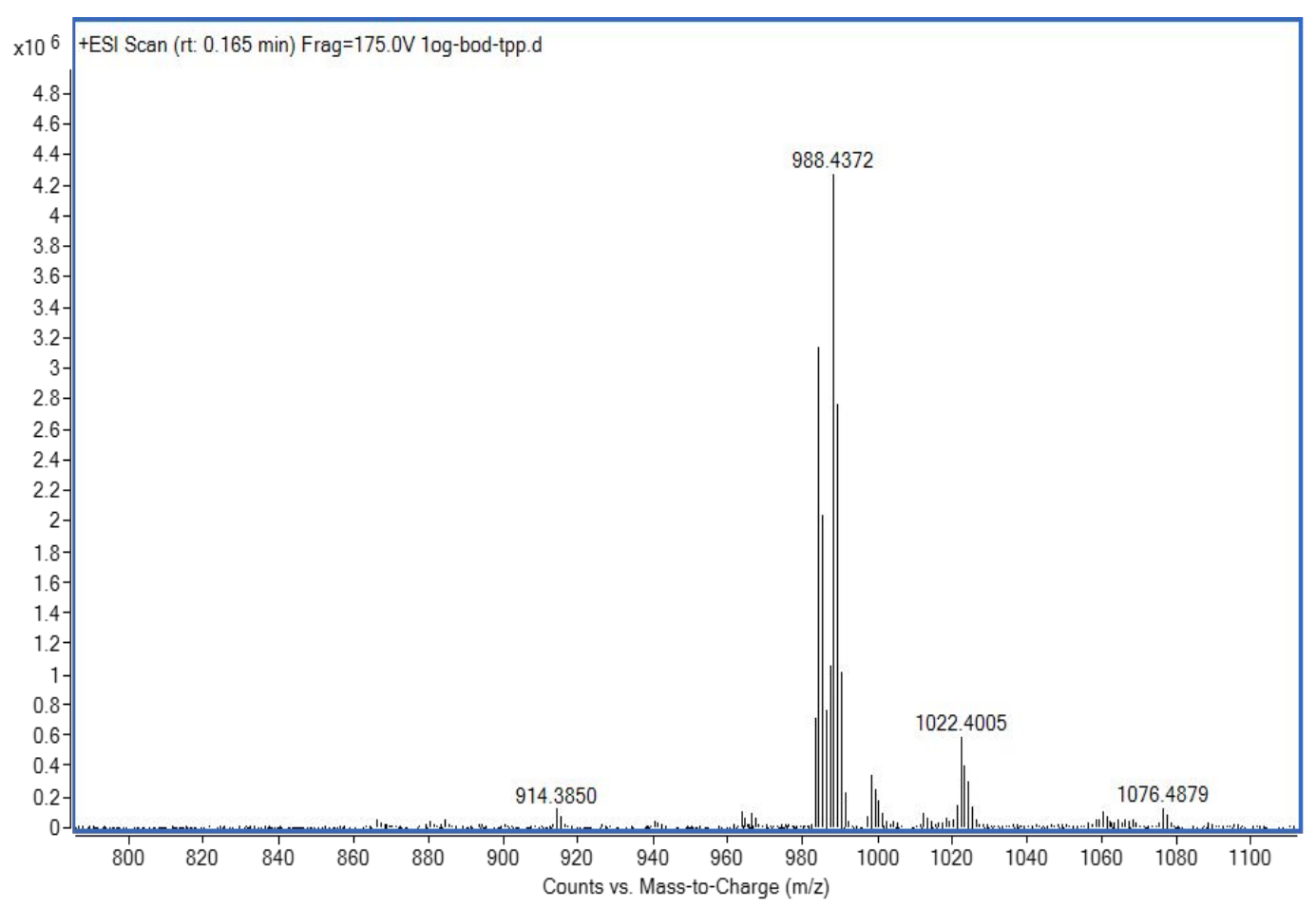

Figure S15. HRMS spectrum of Mito-BDP1.

○ ๙

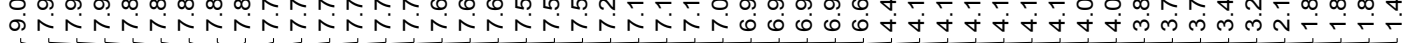

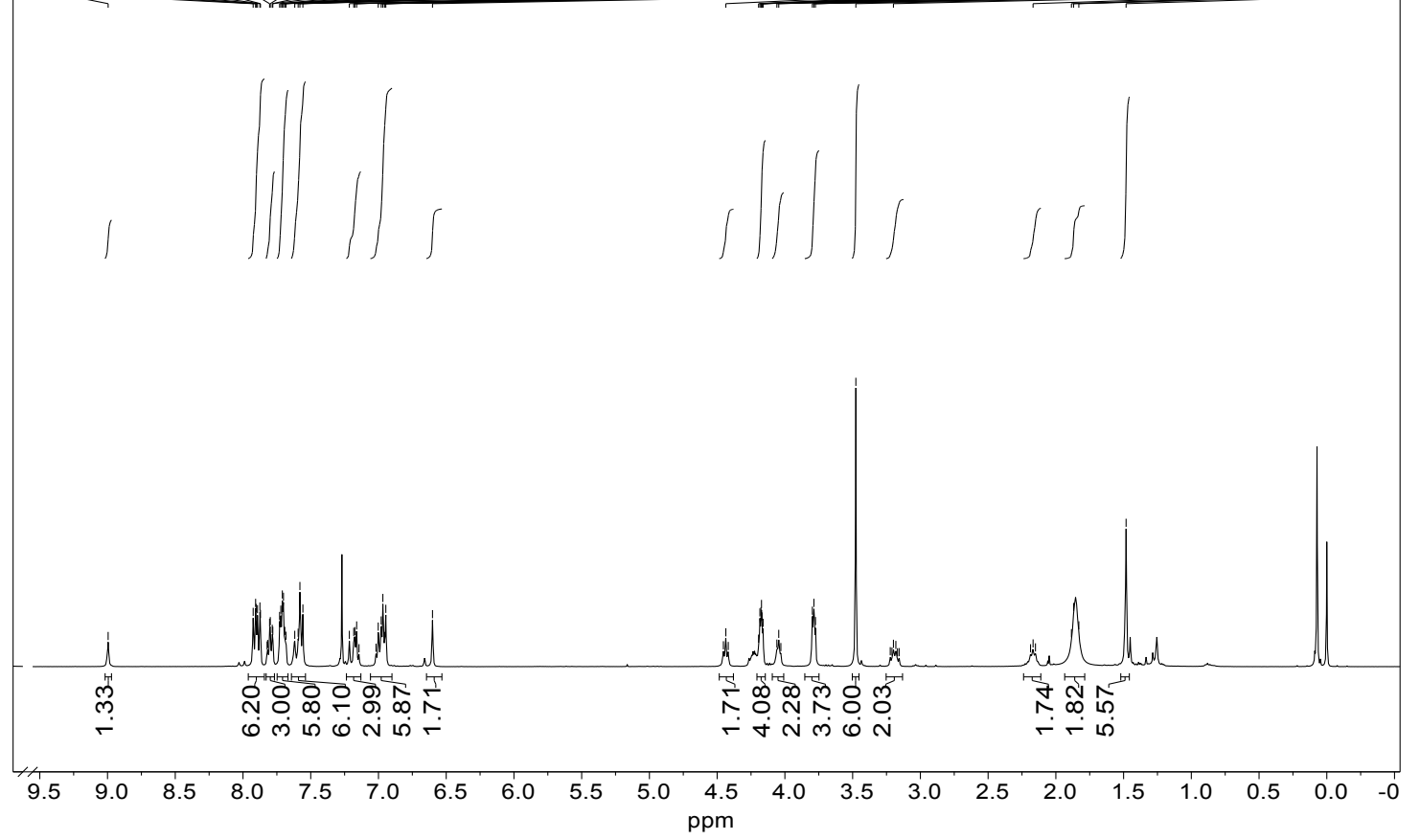

Figure S16. ${ }^{1} \mathrm{H}$ NMR spectrum of Mito-BDP2 in $d$-chloroform. 


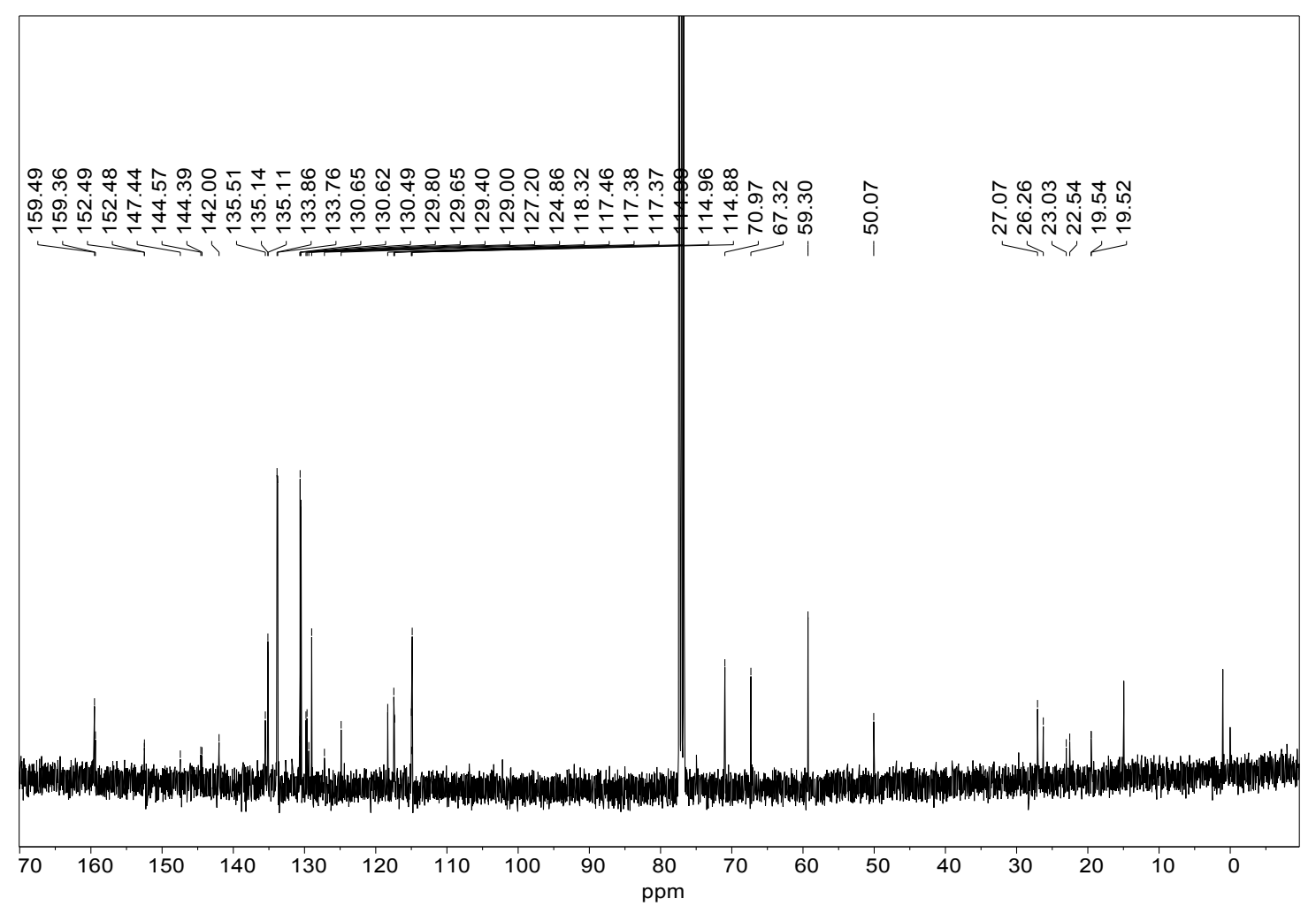

Figure S17. ${ }^{13} \mathrm{C}$ NMR spectrum of Mito-BDP2 in $d$-chloroform.

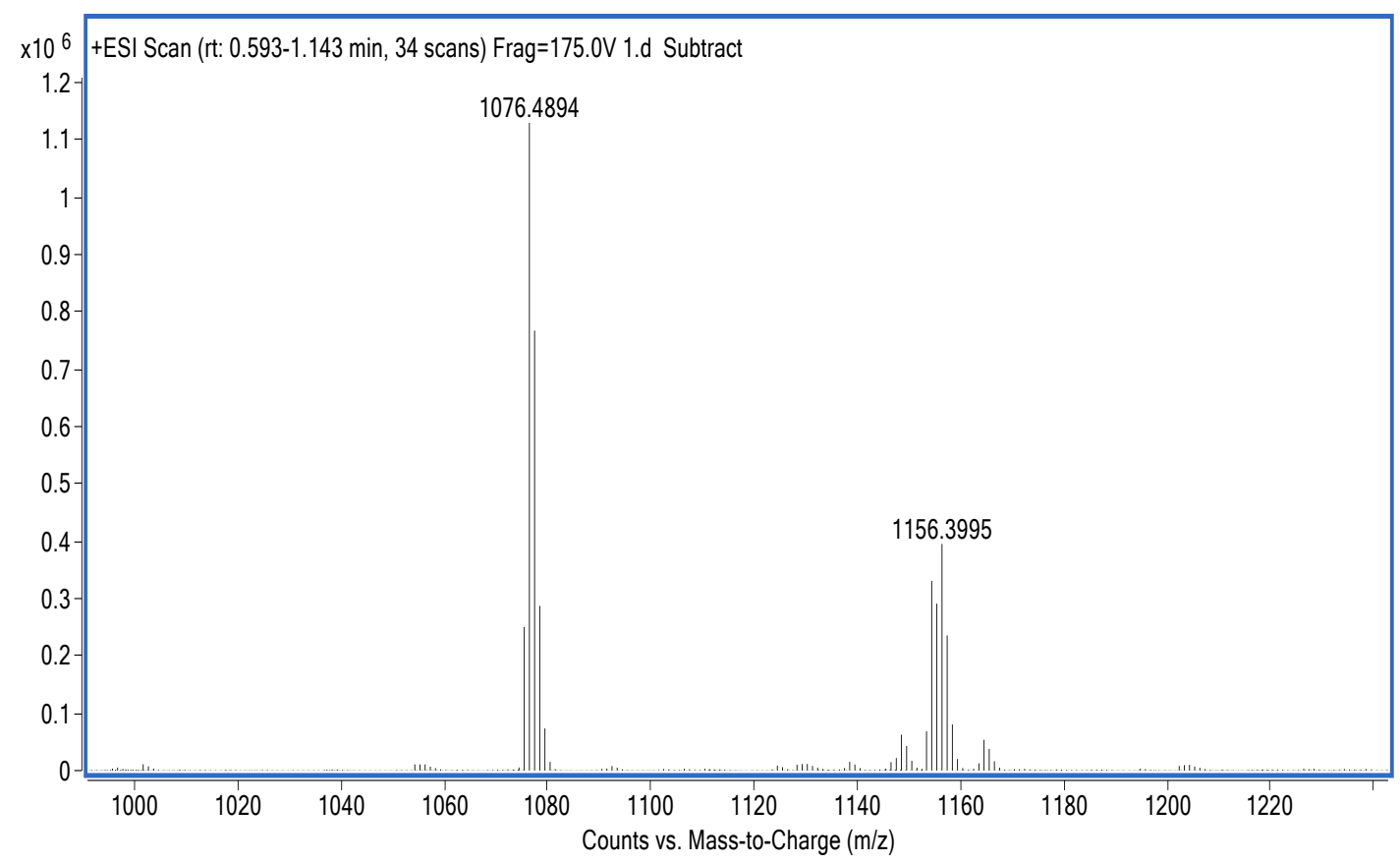

Figure S18. HRMS spectrum of Mito-BDP2. 


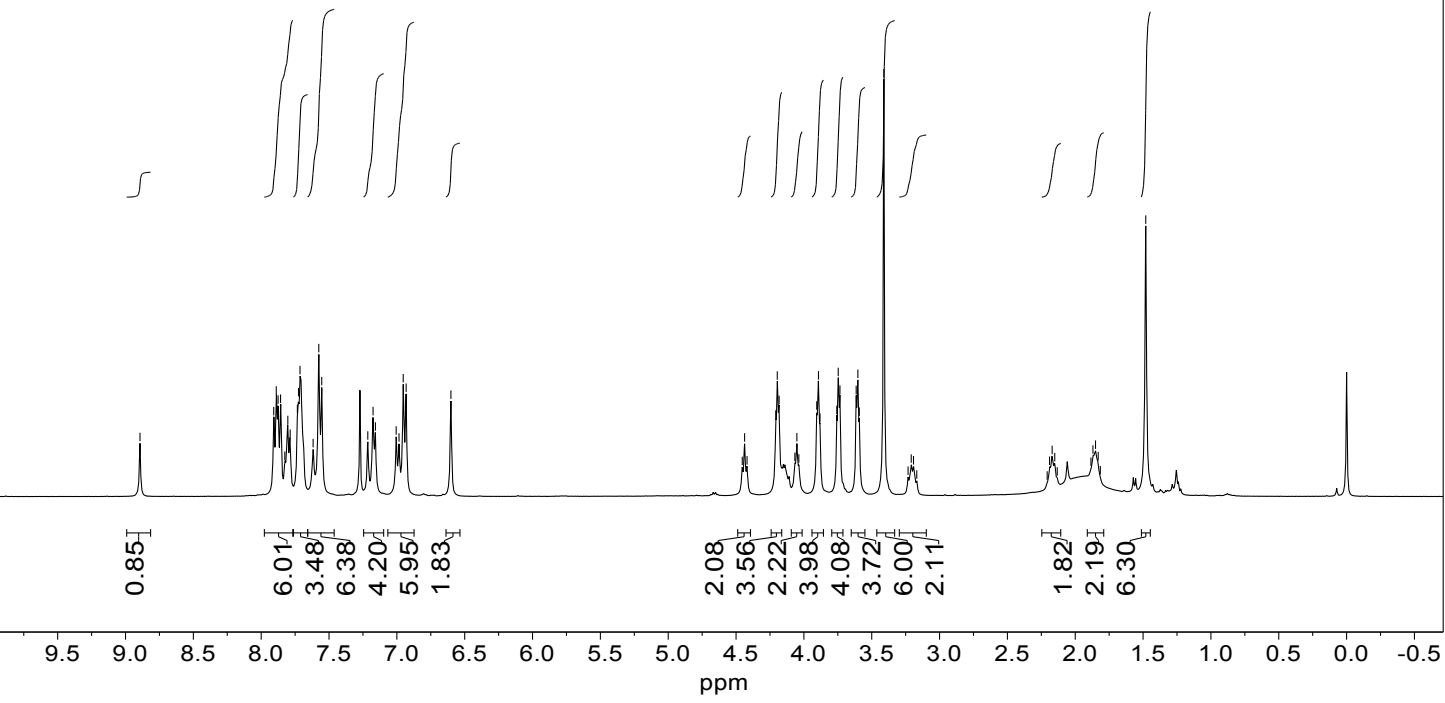

Figure S19. ${ }^{1} \mathrm{H}$ NMR spectrum of Mito-BDP3 in $d$-chloroform.

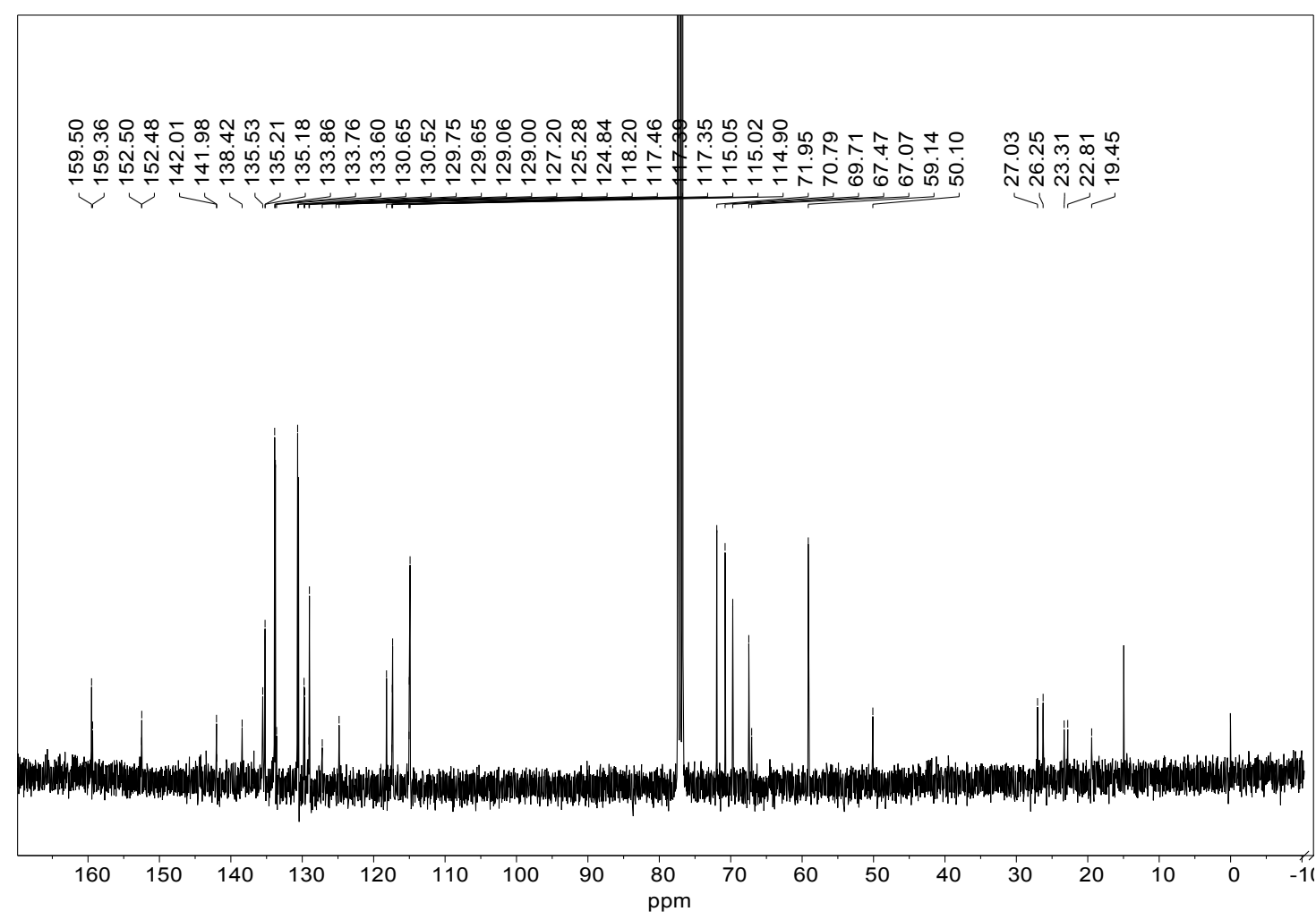

Figure S20. ${ }^{13} \mathrm{C}$ NMR spectrum of Mito-BDP3 in $d$-chloroform. 


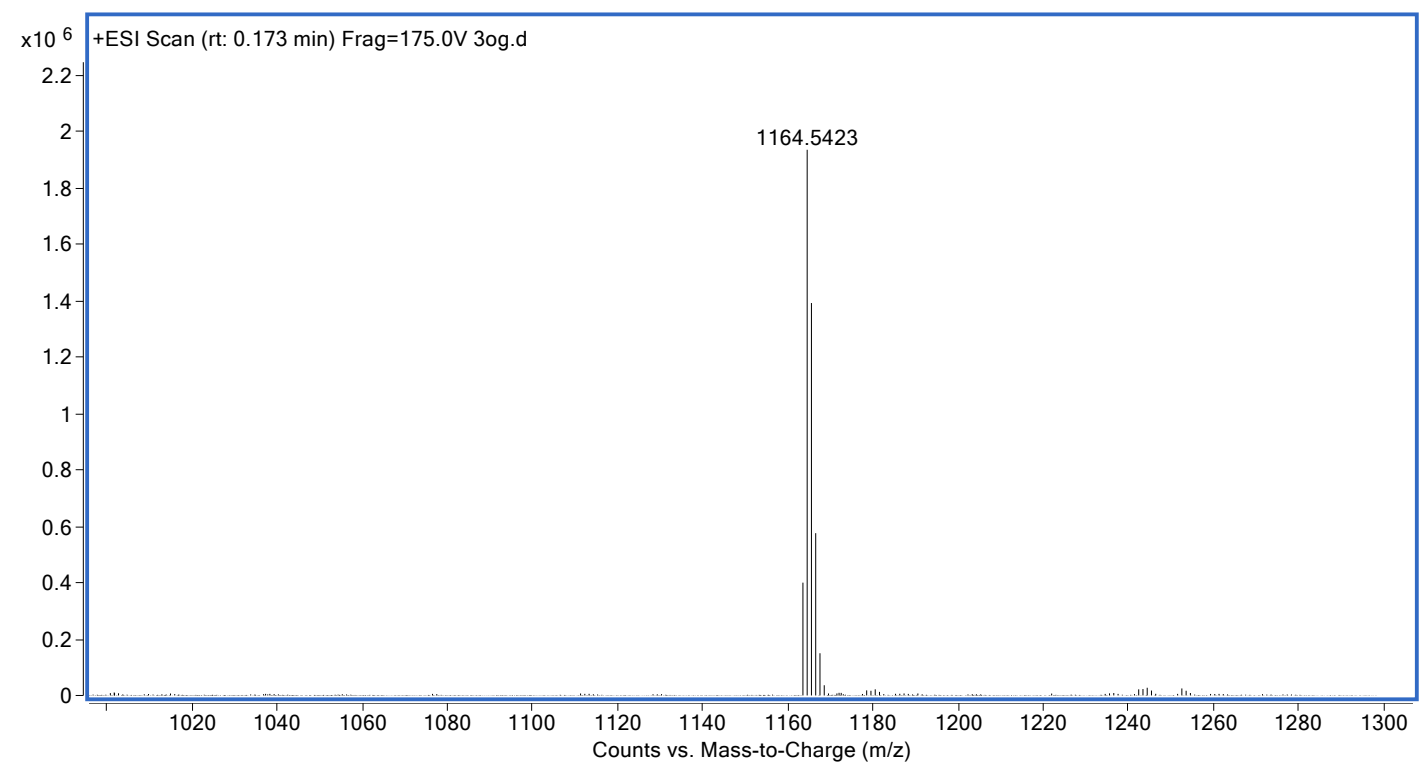

Figure S21. HRMS spectrum of Mito-BDP3.

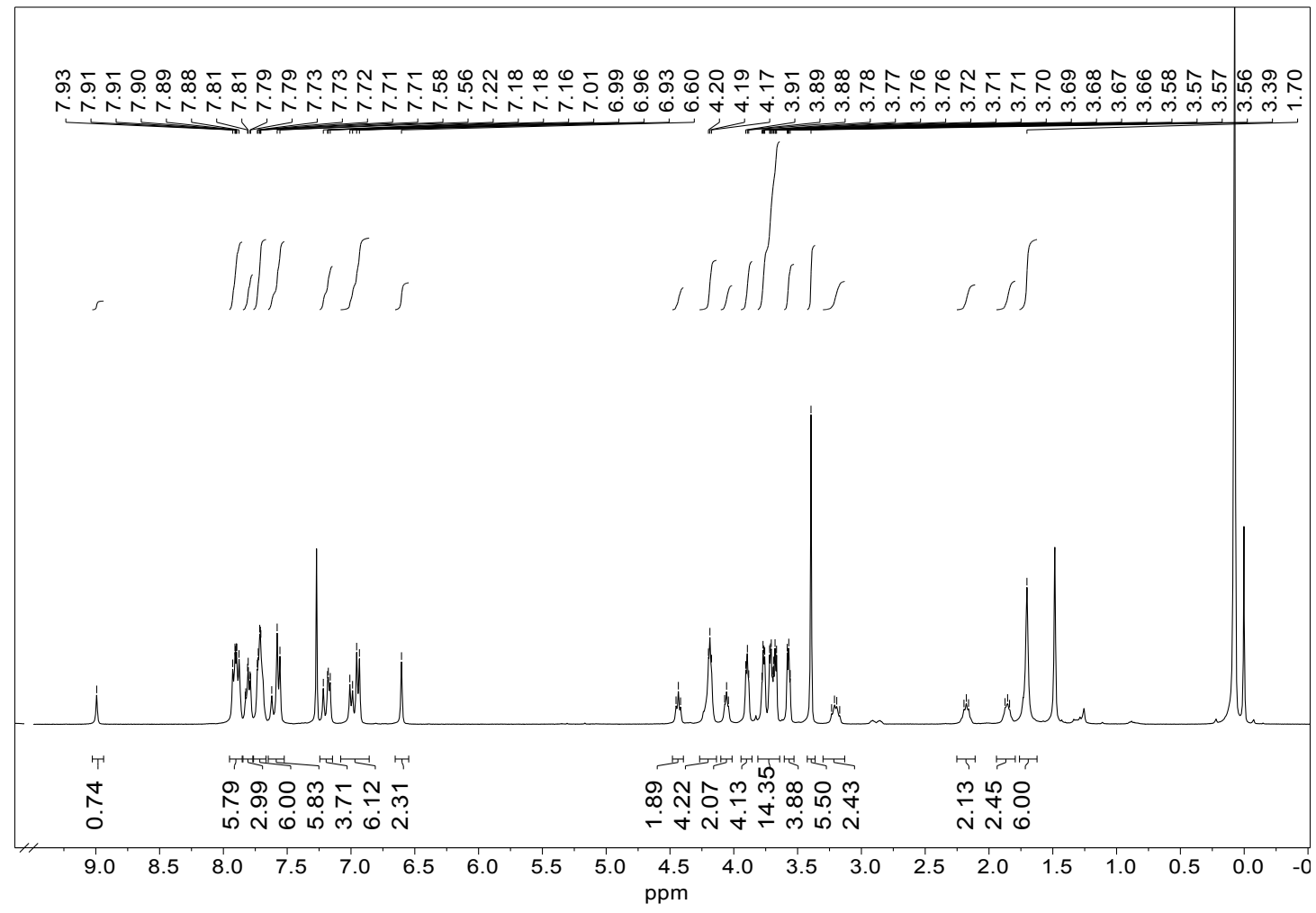

Figure S22. ${ }^{1} \mathrm{H}$ NMR spectrum of Mito-BDP4 in $d$-chloroform. 


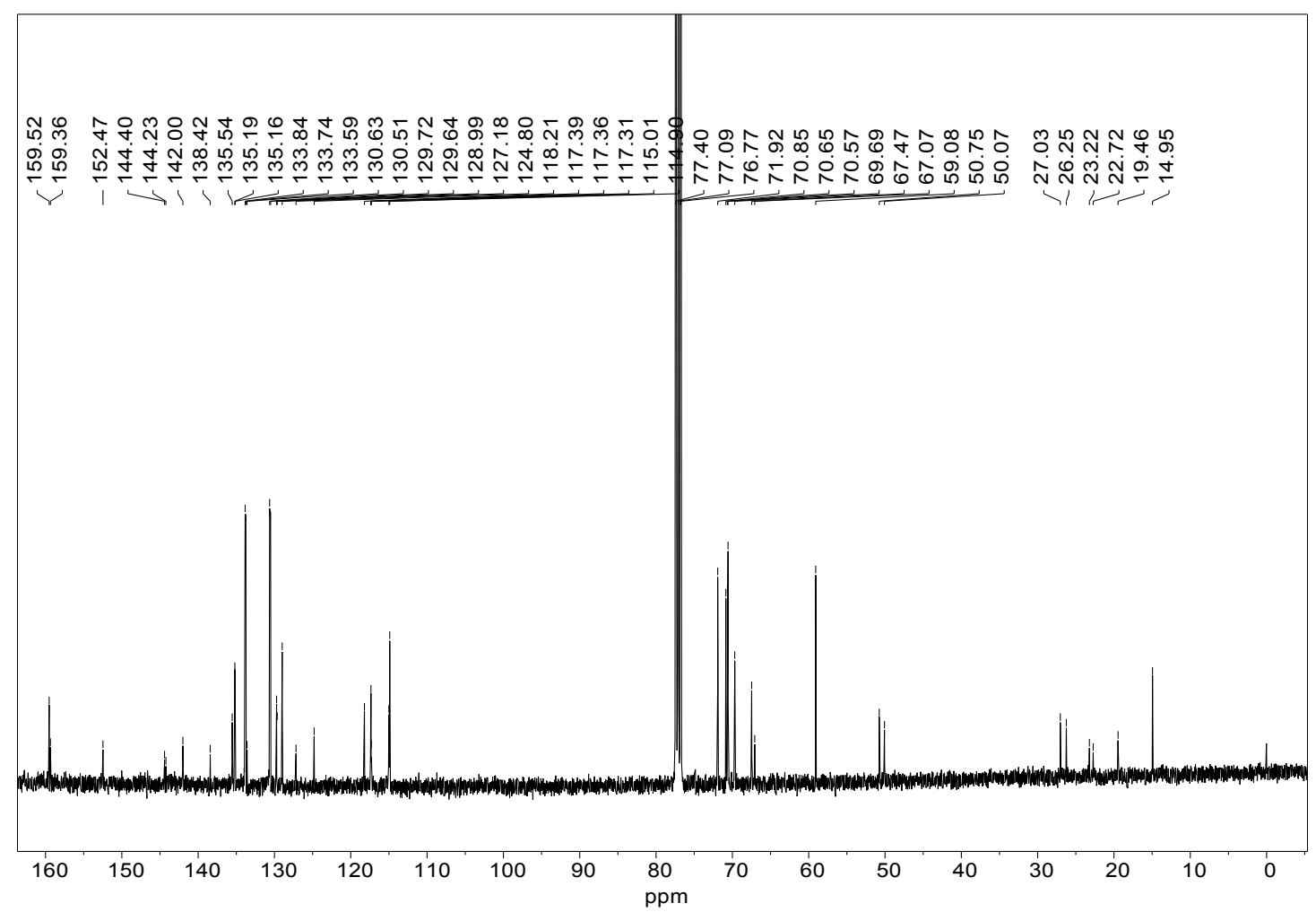

Figure S23. ${ }^{13} \mathrm{C}$ NMR spectrum of Mito-BDP4 in $d$-chloroform.

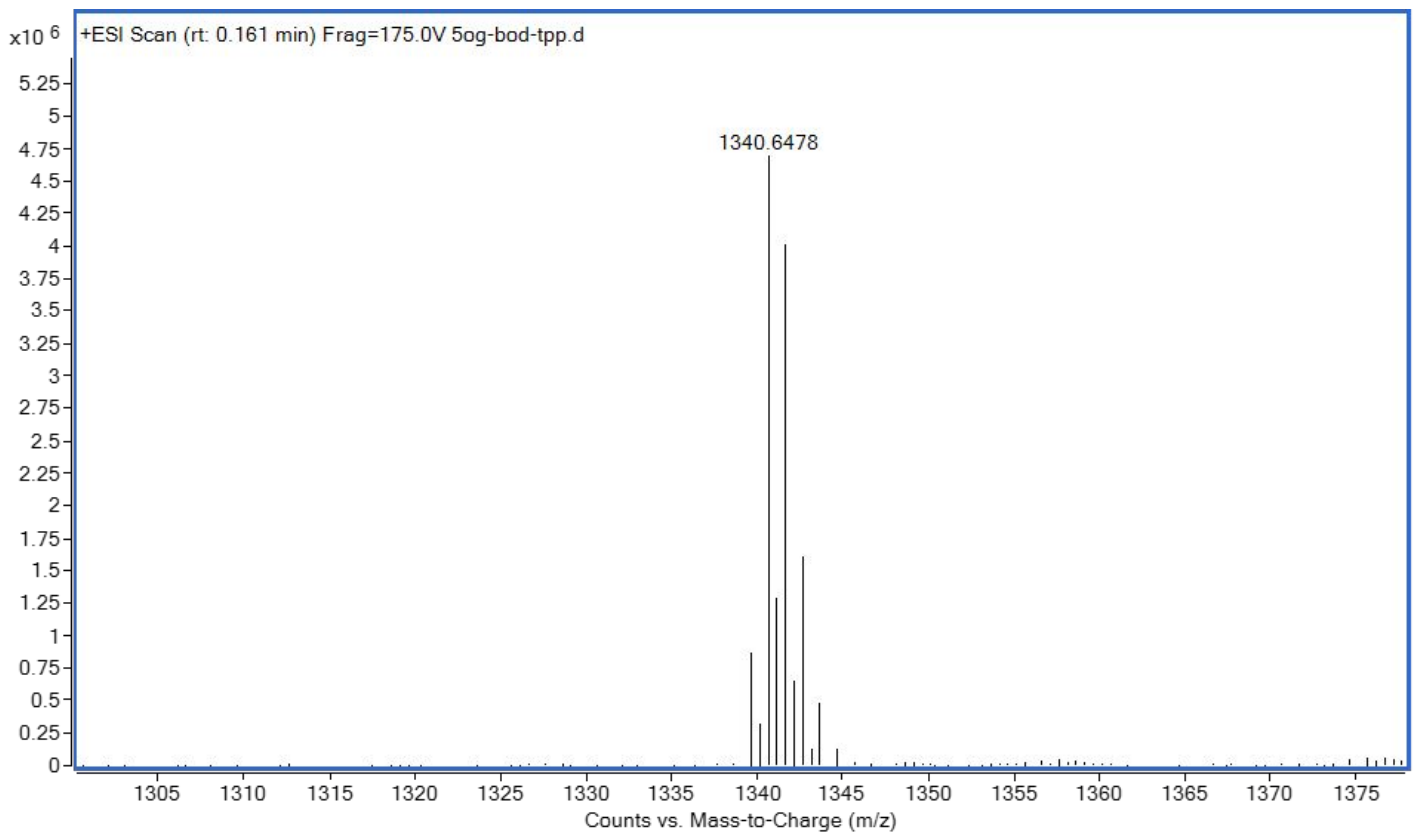

Figure S24. HRMS spectrum of Mito-BDP4. 


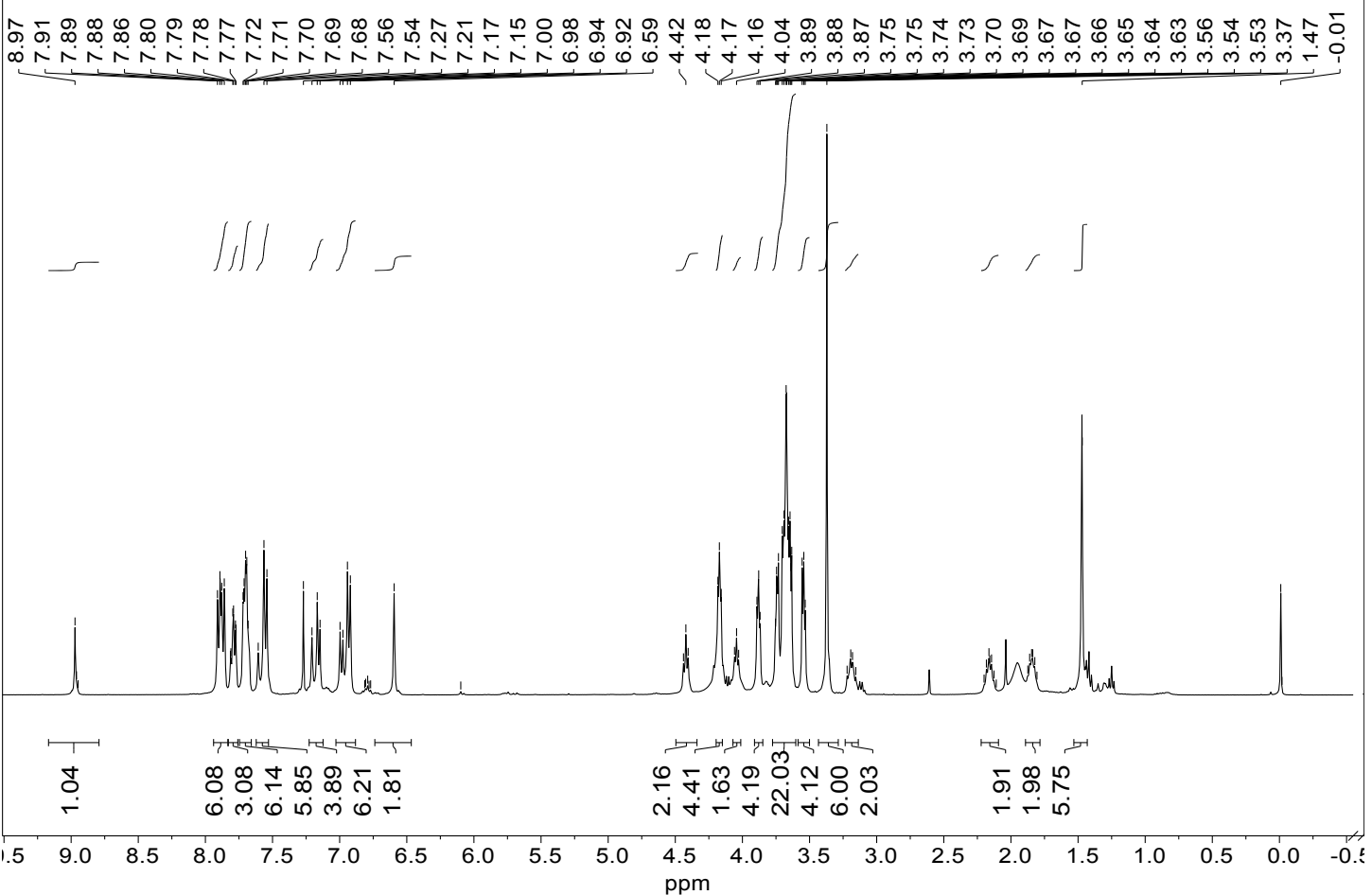

Figure S25. ${ }^{1} \mathrm{H}$ NMR spectrum of Mito-BDP5 in $d$-chloroform.

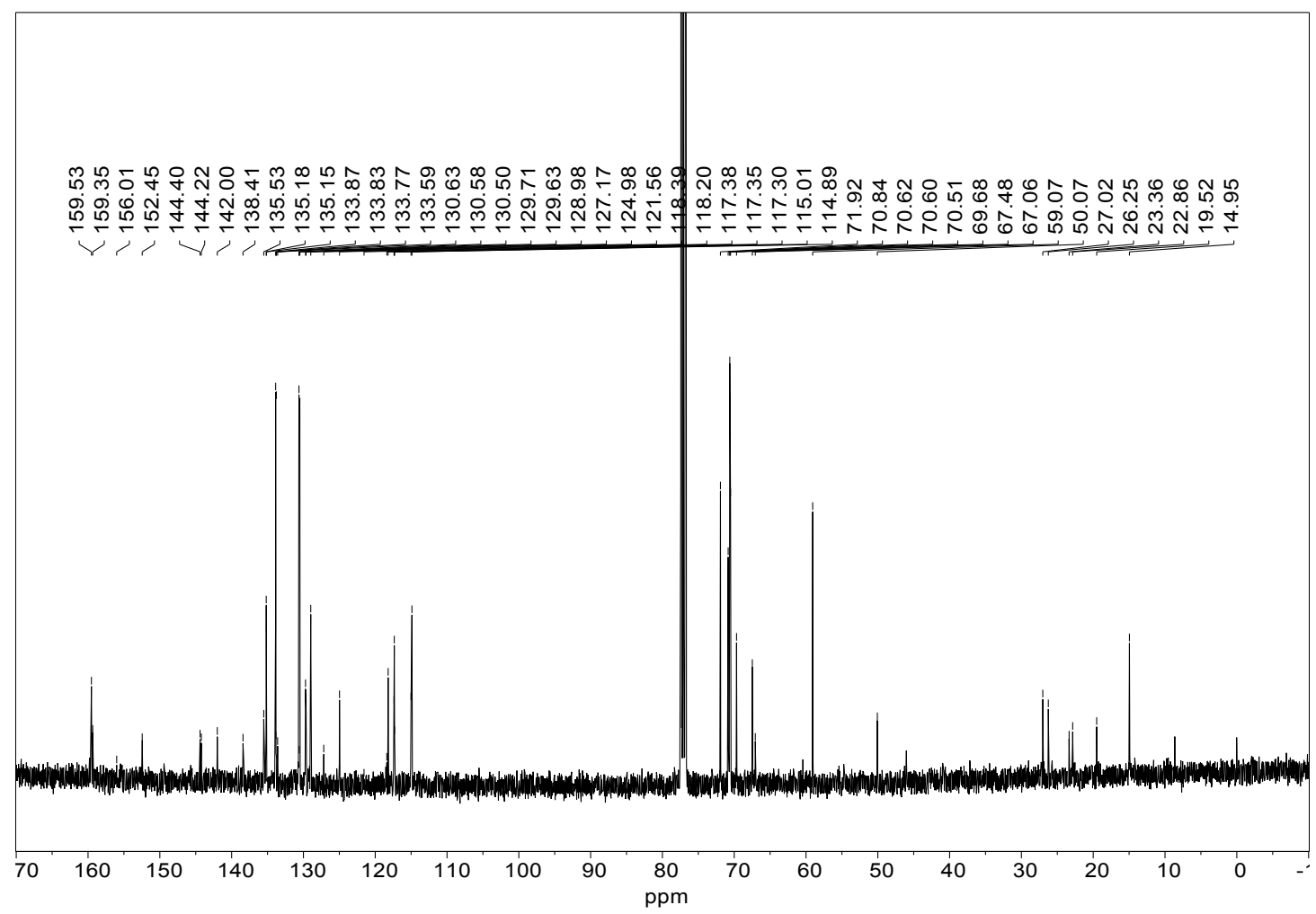

Figure S26. ${ }^{13} \mathrm{C}$ NMR spectrum of Mito-BDP5 in $d$-chloroform. 


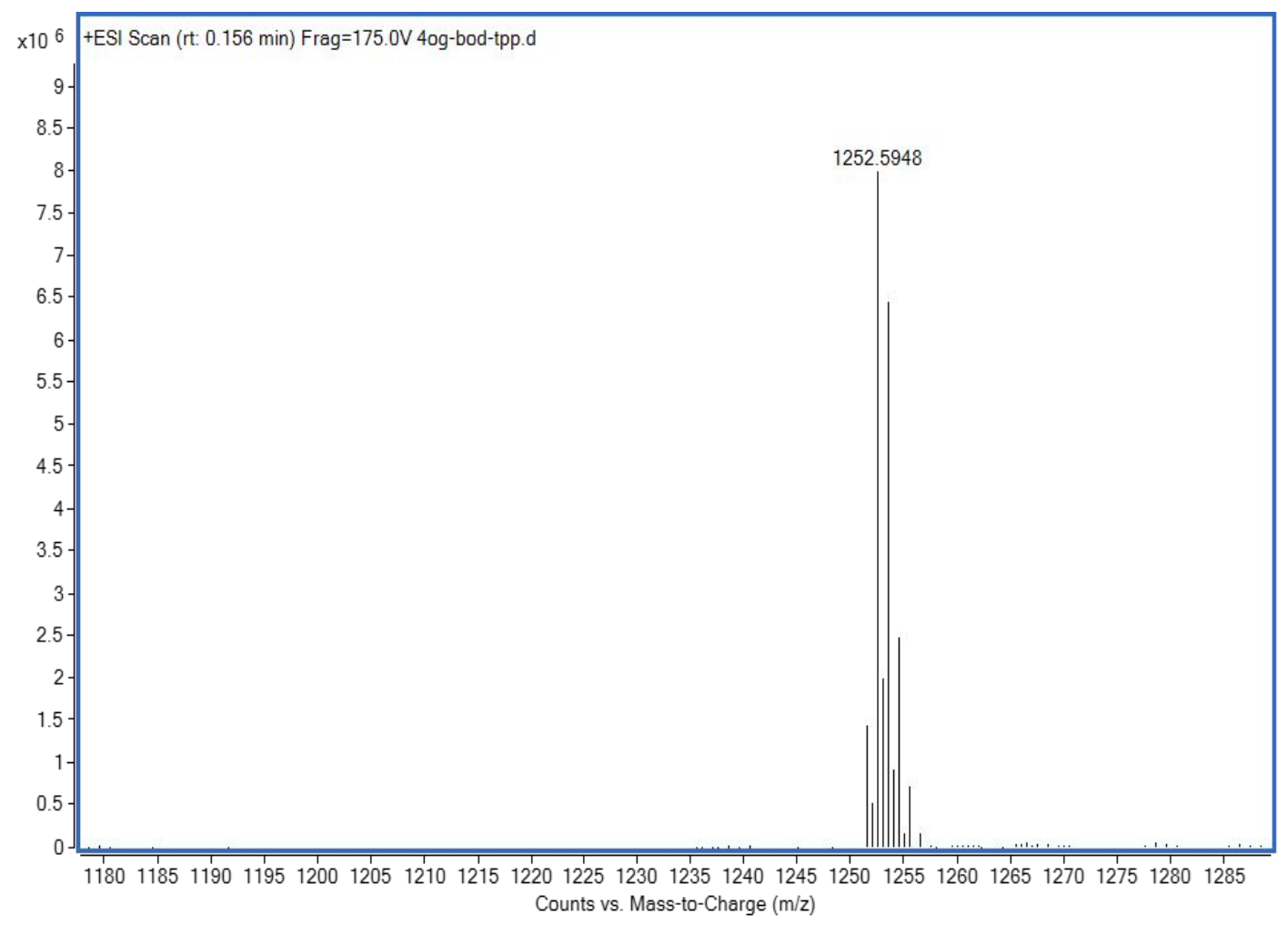

Figure S27. HRMS spectrum of Mito-BDP5.

\section{Calculation of the photothermal conversion efficiency}

The photothermal conversion efficiency (PCE) of BODIPY NPs irradiated at $660 \mathrm{~nm}$ were calculated according to a previously described equation S1: (1)

$P C E=\frac{h s\left(T_{\max }-T_{\text {surr }}\right)-Q_{\text {dis }}}{I\left(1-10^{-A 660}\right)} \quad \cdots . .$. equation $\mathbf{S 1}$

Where $h s$ can be calculated by equation S2:

$h s=\frac{m C}{\tau_{S}} \quad \cdots \cdots \cdot$ equation $\mathbf{S 2}$

Where $\tau_{\mathrm{S}}$ can be calculated by following equation S3:

$\tau=-t \ln \theta \quad \cdots \cdots$ equation $\mathbf{S 3}$

Where $\theta$ can be calculated by following equation S4:

$\theta=\frac{T-T_{\text {surr }}}{T_{\max }-T_{\text {surr }}} \ldots .$. equation $\mathbf{S} 4$ 
Where $T_{\text {surr }}$ is the ambient temperature, $T_{\max }$ represents sample cell reaches the equilibrium temperature, $Q_{d i s}$ was measured independently, $m$ is $0.5 \mathrm{~g}$ and the $C$ is 4.2 $\mathrm{J} / \mathrm{g}, \tau_{\mathrm{s}}$ of five samples calculated by Figure $\mathrm{S} 32, A_{660}$ is measured by $\mathrm{UV}$-vis Figure. $\mathrm{S} 5, I$ is $1.0 \mathrm{~W} \mathrm{~cm}^{-2}$. A quartz sample cell containing pure water was used in the independently determination of $Q_{\text {dis }}(16.9 \mathrm{~mW})$. Consequently, all unknowns are brought into equation 1 to calculate the PCE.
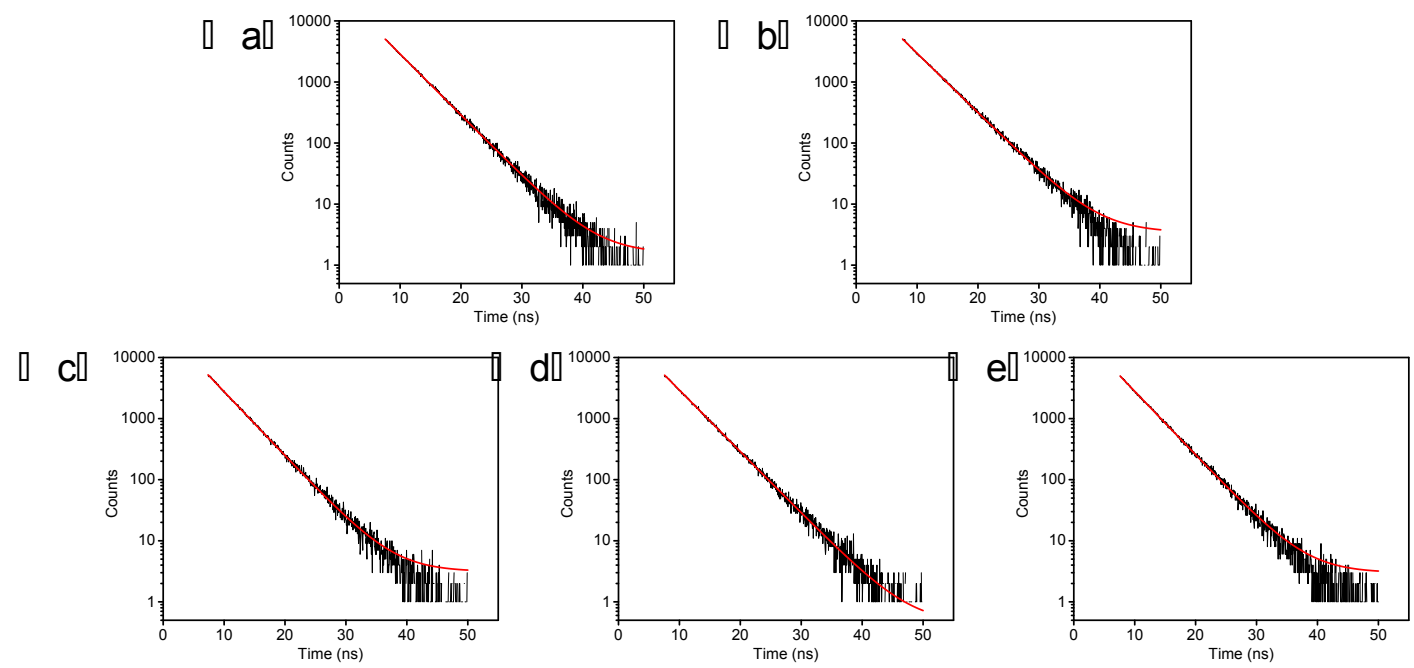

Figure S28. Fluorescence decay profiles of Mito-BDP1-5 (a - e) in DMSO upon excitation at $640 \mathrm{~nm}$. 

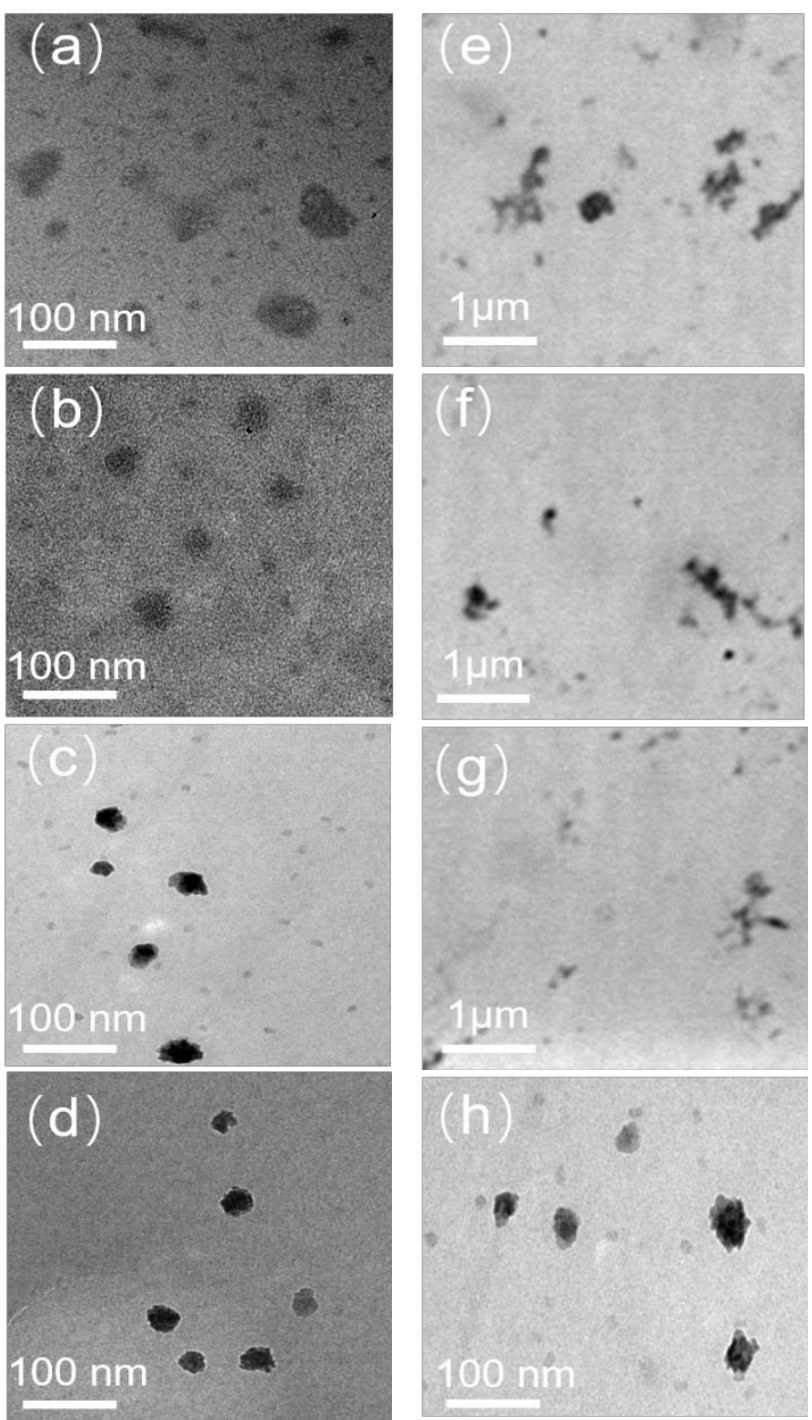

Figure S29. TEM images of Mito-BDP2-4 NPs and HO-BDP5 NPs. (a-d) Mito-BDP2-4 NPs and HO-BDP5 NPs were ultrasonicated for $30 \mathrm{~min}$. (e-h) Mito-BDP2-4 NPs and HO-BDP5 NPs were let stand for several hours. 
(a)

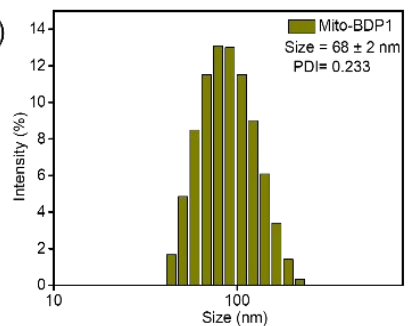

(d)

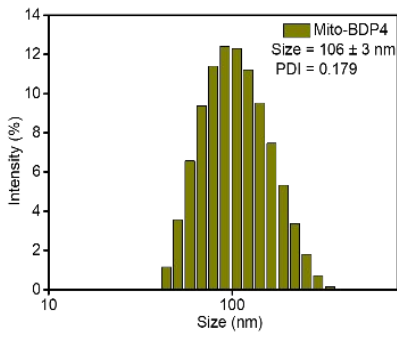

(b)

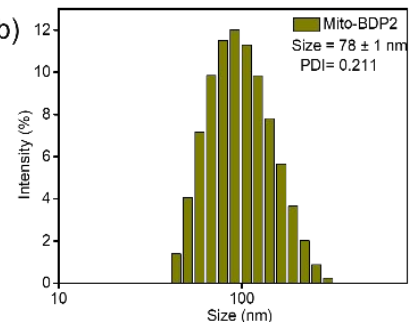

(e)

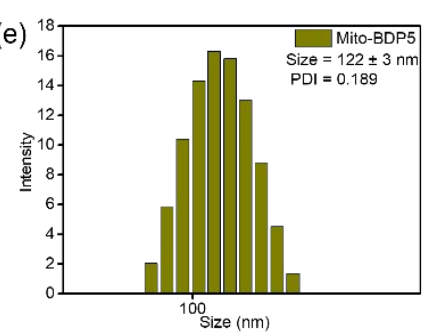

(c)

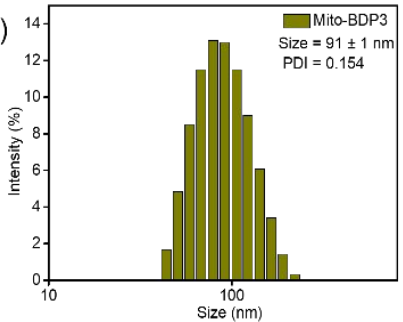

(f)

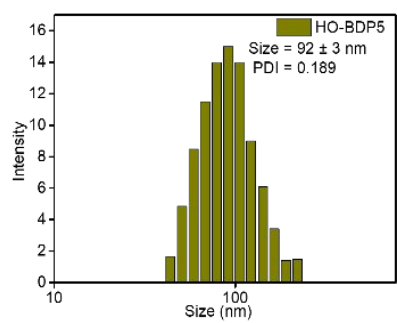

Figure S30. (a-f) Particle size distribution of Mito-BDP1-5 NPs and HO-BDP5 NPs were measured by DLS.

(a)

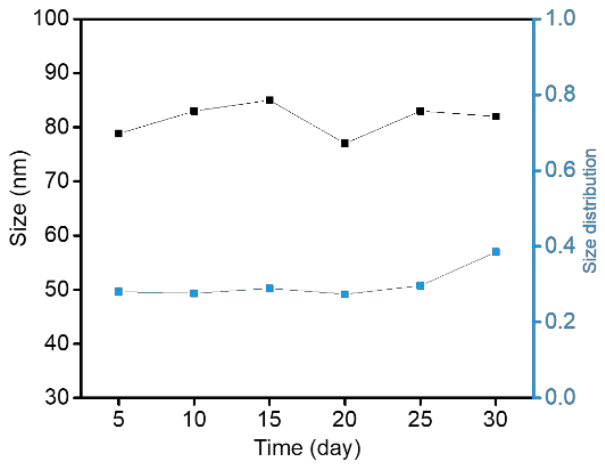

(b)

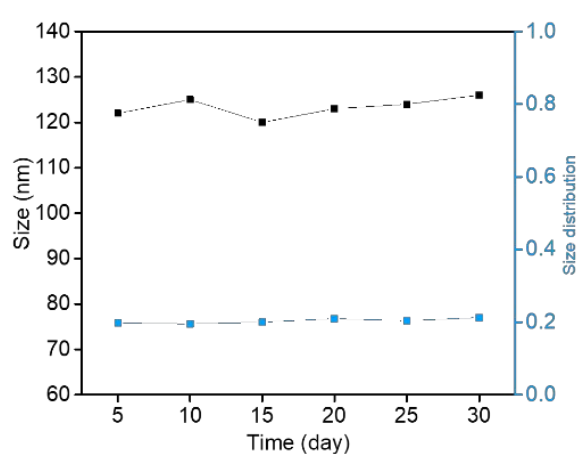

Figure S31. (a-b) Particle size and PDI of Mito-BDP5 and HO-BDP5 NPs were measured by DLS at different times $(0,5,10,15,20,25,30$ days). 

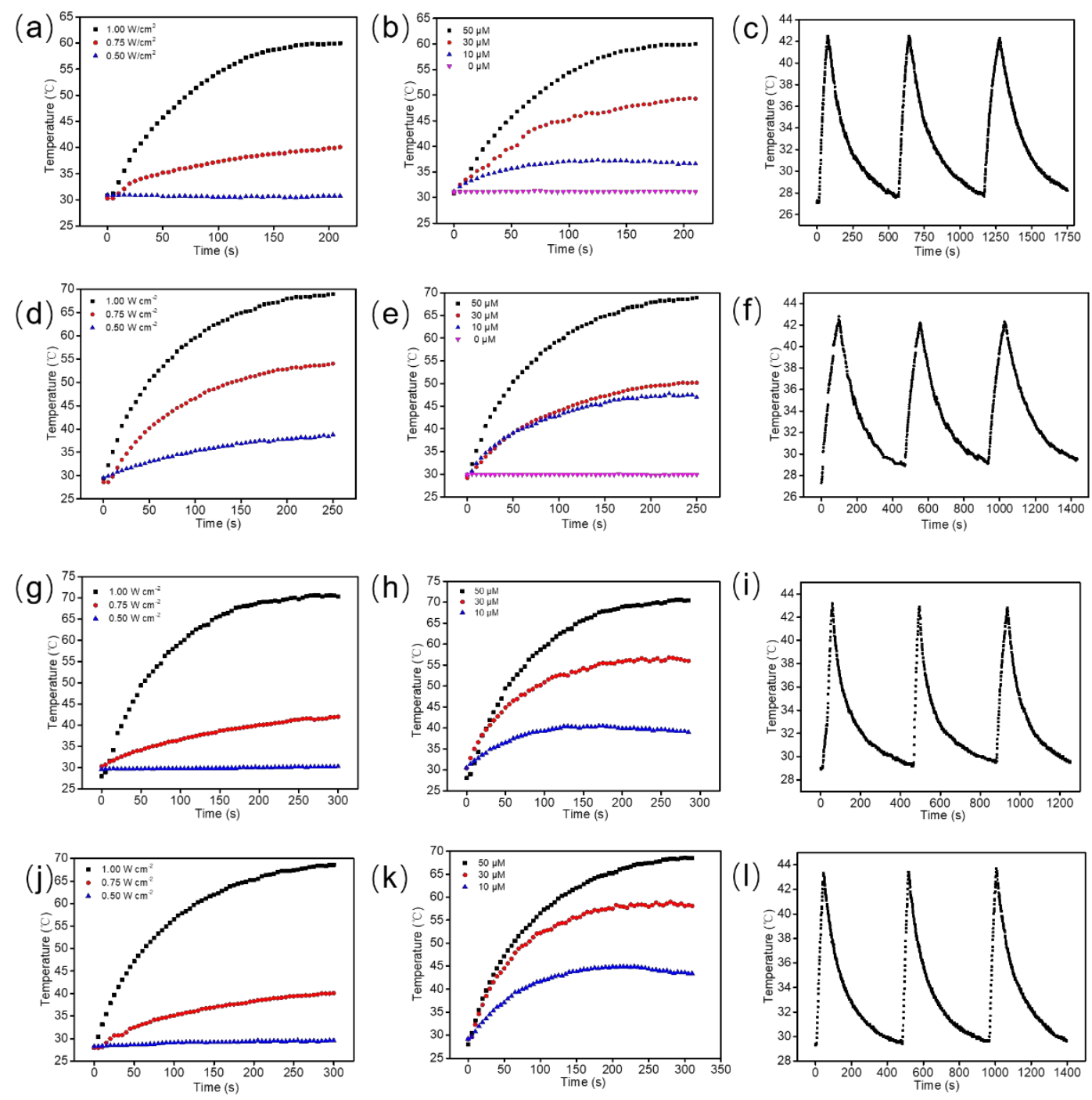

Figure S32. (a), (d), (g) and (j) Photothermal heating curves of Mito-BDP1-4 NPs $(50 \mu \mathrm{M})$ under $660 \mathrm{~nm}$ laser irradiation with different laser power densities. (b), (e), (h) and (k) Photothermal heating curves of Mito-BDP1-4 NPs with different concentrations upon $660 \mathrm{~nm}$ laser irradiation $\left(1.0 \mathrm{~W} \mathrm{~cm}^{-2}\right)$. (c), (f), (i) and (1) Temperature variations of the Mito-BDP1-4 NPs upon laser irradiation under a power density of $1.0 \mathrm{~W} \mathrm{~cm}^{-2}$ for three on/off cycles. 
I all

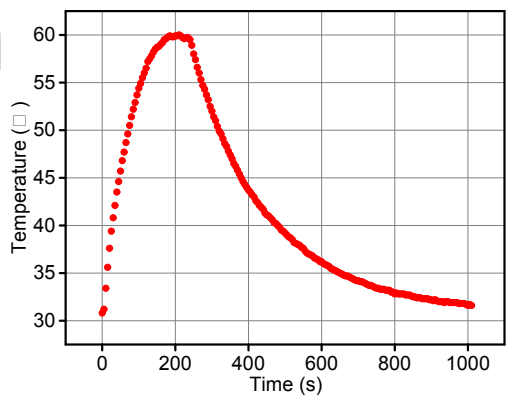

प Cl

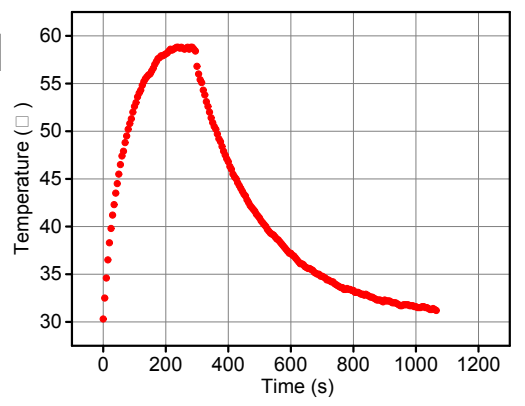

प el

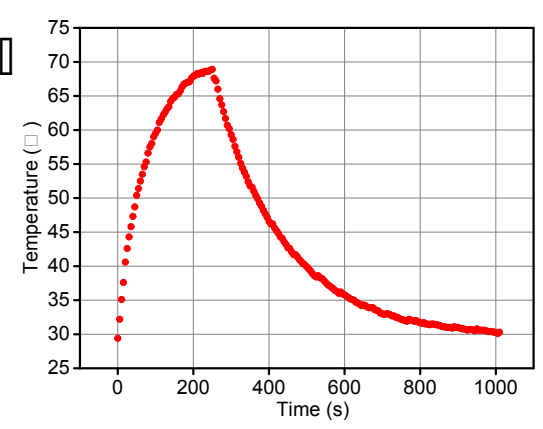

प g】

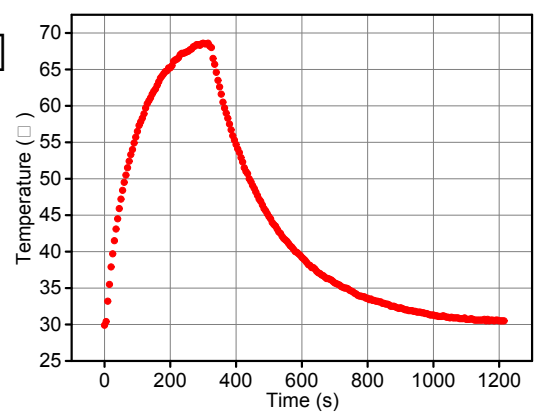

प bl

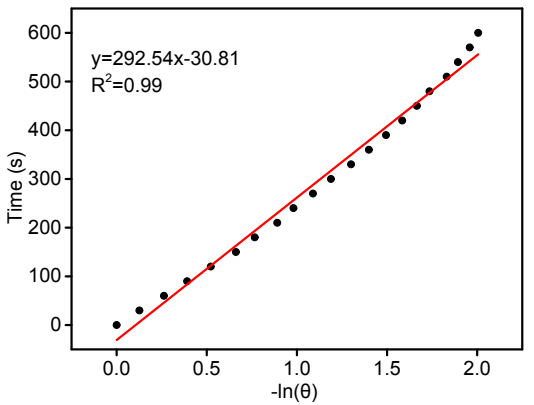

प] dl

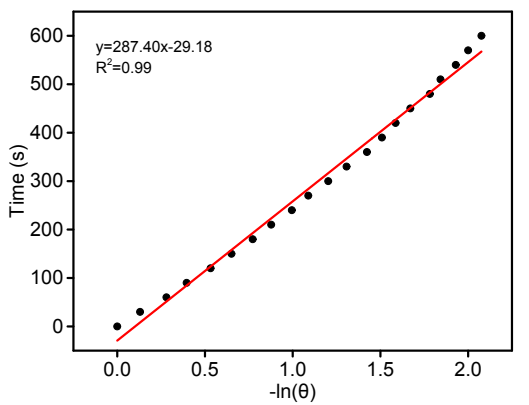

1) f

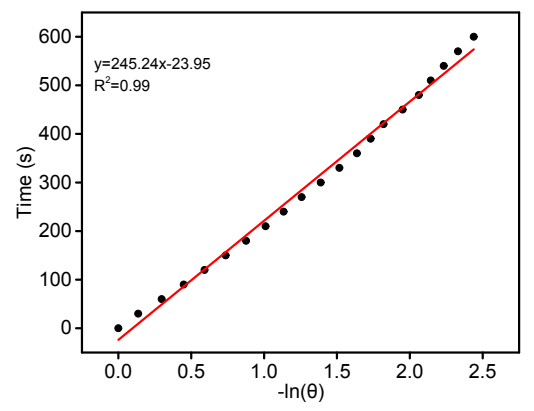

प h!

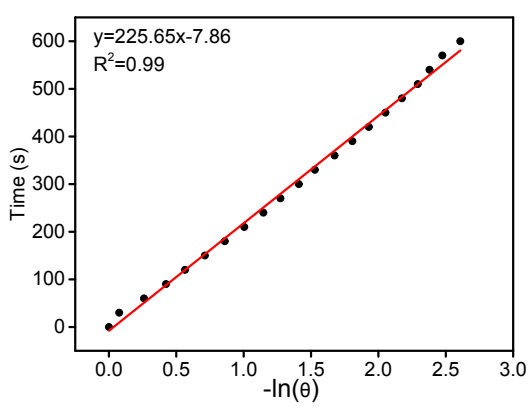

Figure S33. Photothermal effect of the Mito-BDP1-4 NPs in PBS under irradiation of a $660 \mathrm{~nm}$ laser $\left(1.0 \mathrm{~W} \mathrm{~cm}^{-2}\right)$, which was turned off after irradiation. Time versus $-\ln (\theta)$ plot (with $\theta$ being the driving force temperature). (b), (d), (f) and (h) were obtained with the data recorded during the cooling period in (a), (c), (e) and (g). 


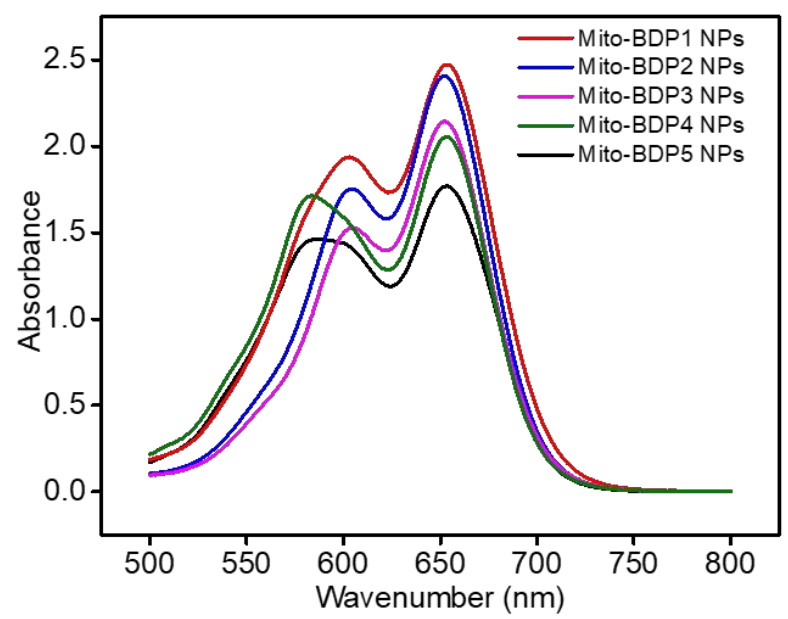

Figure S34. UV-vis absorption spectral of Mito-BDP1-5 NPs $(50 \mu \mathrm{M})$.

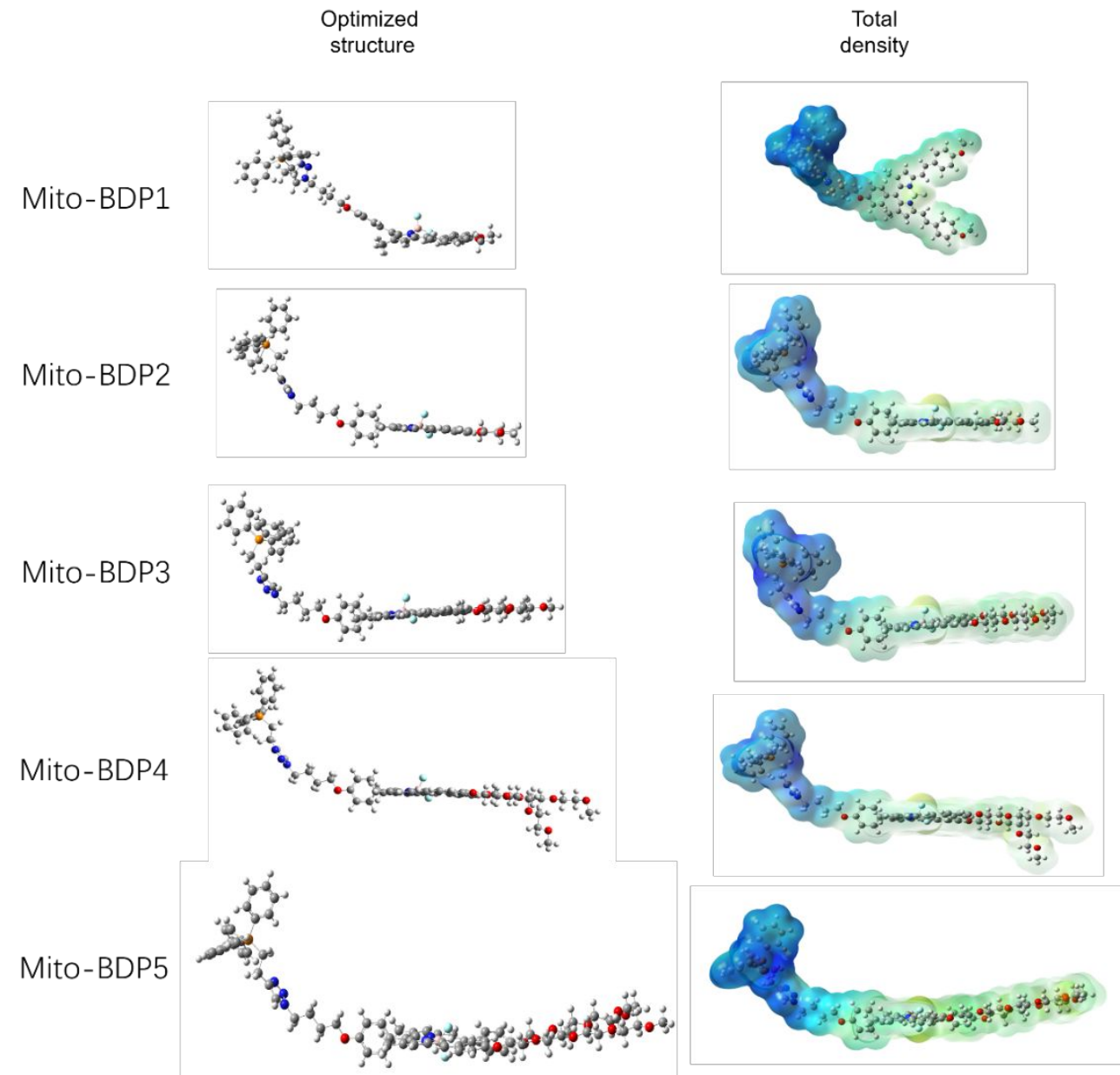

Figure S35. Optimized structure and total density of Mito-BDP1-5. 


\section{References}

(1) Zhang, Y. D.; Song, N.; Li, Y. Y.; Yang, Z. Y.; Chen, L.; Sun, T. T.; Li Y, et al. Comparative study of two near-infrared coumarin-BODIPY dyes for bioimaging and photothermal therapy of cancer. J. Mat. Chem. B, 2019, 7, 4717-4724.

(2) Zhang, W.; Lin, W.; Li, C.; Liu, S.; Xie, Z. G. Rational design of BODIPY-Diketopyrrolopyrrole conjugated polymers for photothermal tumor ablation. ACS Appl. Mater. Interfaces, 2019, 11, 32720-32728.

(3) Zhu, J. W.; Zou, J. H.; Zhang, Z. J.; Zhang, J.; Sun, Y.; Dong, X. C.; Zhang, Q. An NIR triphenylamine grafted BODIPY derivative with high photothermal conversion efficiency and singlet oxygen generation for imaging guided phototherapy. Mater. Chem. Front., 2019, 3, 1523-1531.

(4) Ye, S. Y.; Rao, J. M.; Qiu, S. H.; Zhao, J. L.; He, H.; Yan, Z. L.; Yang, T.; Deng, Y. B.; Ke, H. t.; Yang, H.; Zhao, Y L.; Guo, Z. Q.; Chen, H. B. Rational design of conjugated photosensitizers with controllable photoconversion for dually cooperative phototherapy. Adv. Mater., 2018, 30, 1801216.

(5) Xi, D. M.; Xiao, M.; Cao, J. F.; Zhao, L. Y.; Xu, N.; Long, S.; Fan, J. L.; Shao, K.; Sun, W.; Yan, W. H.; Peng, X. J. NIR light-driving barrier-free group rotation in nanoparticles with an $88.3 \%$ photothermal conversion efficiency for photothermal therapy. Adv. Mater., 2020, 32, 1907855.

(6) Wu, C. L.; Huang, X. Y.; Yang, Y. Y.; Xiao, W, Y.; Sun, L. G.; Shao, J. J.; Dong. X. C. Pyrrolopyrrole aza-BODIPY near-infrared photosensitizer for dual-mode imaging-guided photothermal cancer therapy. Chem. Commun. 2019, 55, 790-793.

(7) Chen, D. P.; Tang, Q. Y.; Zou, J. H.; Yang, X. Y.; Huang, W.; Zhang, Q.; Shao, J. J.; Dong, X. C. pH - responsive PEG-doxorubicin - encapsulated aza - BODIPY nanotheranostic agent for imaging-guided synergistic cancer therapy. $A d v$. Healthc. Mater. 2018, 7, 1701272.

(8) Wang, X.; Lin, W. H.; Zhang, W.; Li, C.; Sun, T. T.; Chen, G.; Xie, Z. G. Amphiphilic redox-sensitive NIR BODIPY nanoparticles for dual-mode imaging and photothermal therapy. J. Colloid Interface Sci., 2019, 536, 208-214. 
(9) Liu, Y.; Song, N.; Li, Z. S.; Li, C.; Xie, Z. G. Near-infrared nanoparticles based on aza-BDP for photodynamic and photothermal therapy. Dyes Pigments, 2019, 160 ,

(10)Song, N.; Fu, L.; Liu, Y.; Li, Y. Y.; Chen, L.; Wang, X. Y.; Liu, S.; Xie, Z. G. Rational design of BODIPY organic nanoparticles for enhanced photodynamic/photothermal therapy. Dyes Pigments, 2019, 162, 295-302.

(11)Tian, Q. W.; Jiang, F. R.; Zou, R. J.; Liu, Q.; Chen, Z. G.; Zhu, M. F.; Yang, S. P.; Wang, J. L.; Wang, J. H.; Hu, J. Q. Hydrophilic $\mathrm{Cu}_{9} \mathrm{~S}_{5}$ nanocrystals: a photothermal agent with a $25.7 \%$ heat conversion efficiency for photothermal ablation of cancer cells in vivo. ACS Nano, 2011, 5, 9761-9771. 